\title{
Molecular Nitrogen Promotes Catalytic Hydrodeoxygenation
}

Haohong Duan ${ }^{1,2,3}$, Jin-Cheng $\mathrm{Liu}^{4}$, Yufei Zhao ${ }^{2,5}$, Ming Xu${ }^{6}$, Xue-Lu Ma ${ }^{4}$, Juncai Dong ${ }^{7}$, Xusheng Zheng $^{8}$, Jianwei Zheng ${ }^{2}$, Christopher S. Allen ${ }^{9,10}$, Mohsen Danaie ${ }^{9,10}$, Yung-Kang Peng ${ }^{11}$, Titipong Issariyakul ${ }^{12}$, Dongliang Chen ${ }^{6}$, Angus I. Kirkland ${ }^{9,10}$, Jean-Charles Buffet ${ }^{1}$, Ding $\mathrm{Ma}^{6}$, Jun $\mathrm{Li}^{4 *}$, Shik Chi Edman Tsang ${ }^{2 *}$ and Dermot O'Hare ${ }^{1 *}$

${ }^{1}$ Chemistry Research Laboratory, Department of Chemistry, University of Oxford, 12 Mansfield Road, Oxford, OX1 3TA, UK.

${ }^{2}$ The Wolfson Catalysis Centre, Department of Chemistry, University of Oxford, Oxford, OX1 3QR, UK.

${ }^{3}$ Department of Chemistry, Tsinghua University, 30 Shuangqing Rd, Haidian Qu, Beijing Shi 100084, China.

${ }^{4}$ Department of Chemistry and Key Laboratory of Organic Optoelectronics \& Molecular Engineering of Ministry of Education, Tsinghua University, Beijing, 100084, China

${ }^{5}$ State Key Laboratory of Chemical Resource Engineering, Beijing University of Chemical Technology, Beijing 100029, P. R. China

${ }^{6}$ Beijing National Laboratory for Molecular Engineering, College of Chemistry and Molecular Engineering and College of Engineering, BIC-ESAT, Peking University, Beijing 100871, P. R. China ${ }^{7}$ Beijing Synchrotron Radiation Facility, Institute of High Energy Physics, Chinese Academy of Sciences, 19B Yuquan Road, Shijingshan District, Beijing, 100049, China.

${ }^{8}$ National Synchrotron Radiation Laboratory, University of Science and Technology of China, 42 Hezuohua Road, Hefei, Anhui, 230029, China.

${ }^{9}$ Department of Materials, University of Oxford, Parks Road, Oxford, OX1 3PH, UK.

${ }^{10}$ Electron Physical Sciences Imaging Centre (ePSIC), Diamond Light Source, Didcot, Oxford, OX11 ODE, UK

${ }^{11}$ Department of Chemistry, City University of Hong Kong, Yeung Kin Man Academic Building, Hong Kong, B6704, China.

${ }^{12}$ Product \& Technology Development Center, SCG Packaging Public Company Limited, 19 Moo 19 Seang-Xuto Road, ThaPha BanPong Ratchaburi, 70110, Thailand.

Haohong Duan, Jin-Cheng Liu and Yufei Zhao contributed equally to this work.

Correspondence and requests for materials should be addressed to D.O'H. (email: dermot.ohare@chem.ox.ac.uk), to S.C.E.T. (email: edman.tsang@chem.ox.ac.uk) or to J.L. (email: junli@tsinghua.edu.cn) 


\begin{abstract}
While molecular dinitrogen $\left(\mathrm{N}_{2}\right)$ is widely used as a carrier or inert gas for many catalytic reactions, it is rarely considered as catalytic promoter. Here, we report that $\mathrm{N}_{2}$ could be used to promote the catalytic activity and reduce the activation energy for catalytic hydrodeoxygenation (HDO). Hydrodeoxygenation is emerging as important approach for the production of fuels and chemicals (such as benzene, toluene, and other aromatics with high octane numbers) from cheap and renewable lignocellulosic biomass. In our work, we report a 4.3-fold activity increase in catalytic hydrodeoxygenation of $p$-cresol to toluene over a titanium oxide supported ruthenium catalyst $\left(\mathrm{Ru} / \mathrm{TiO}_{2}\right)$ by simply introducing 6 bar $\mathrm{N}_{2}$ under batch conditions at 160 degrees Celsius and 1 bar hydrogen. Detail investigations indicate that $\mathrm{N}_{2}$ can be adsorbed and activated on metallic Ru surface to form hydrogenated nitrogen species, which offers protic hydrogen to lower the activation energy direct carbon $_{(\text {aromatic }}-0 x y g e n$ bond scission and hydrogenation of hydroxyl. Importantly, we demonstrated $\mathrm{N}_{2}$ could also promote HDO activity over a variety of $\mathrm{Ru}$ catalysts on different supports including $\mathrm{Ru} / \mathrm{TiO}_{2}, \mathrm{Ru} / \mathrm{Al}_{2} \mathrm{O}_{3}, \mathrm{Ru} / \mathrm{ZrO}_{2}$ and $\mathrm{Ru} / \mathrm{C}$. These results suggest that $\mathrm{N}_{2}$ promotion of $\mathrm{HDO}$ using $\mathrm{Ru}$ catalysts could be a general strategy to enhance new and existing HDO performance. $N_{2}$ is no longer a simple carrier gas in this chemistry.
\end{abstract}

\title{
Introduction
}

Molecular nitrogen $\left(\mathrm{N}_{2}\right)$ is widely used as a carrier or protective gas for many catalytic reactions because it is cheap, easy to produce from liquefaction of air and more importantly, considered as inert due to the strength of the $\mathrm{N}_{2}$ triple bond ${ }^{1}$. In some special cases, $\mathrm{N}_{2}$ participates in reaction and is catalytically converted to ammonia ${ }^{2}$ or high value nitrogen compounds such as $\mathrm{N}$-heterocycles ${ }^{3}$ and amines $^{4}$. A typical heterogeneous catalytic reaction consists of two or three phases, including solidphase catalyst, gas-phase reactant (e.g. $\mathrm{N}_{2}$ and $\mathrm{H}_{2}$ for ammonia synthesis ${ }^{5,6}, \mathrm{CO}$ and $\mathrm{H}_{2}$ for FischerTropsch synthesis ${ }^{7}$ ) and/or liquid-phase reactant and solvent (e.g. sugars or phenols in organic or aqueous solvent for biomass upgrading ${ }^{8}$ ). The solid-phase catalyst has shown significant development due to its primary role in enhancing the reaction activity. Because the catalysis occurs at the interfacial sites, the species from the other two phases may also affect the catalytic properties. For example, tuning the composition of solvent mixtures in liquid-phase has been shown to enhance rate and selectivity of acid-catalysed dehydration reaction, by altering the solvation extents of the initial and transition states ${ }^{9}$. However, in heterogeneous catalysis $\mathrm{N}_{2}$ from gaseous phase has rarely been recognised as a promoter or an active component to enhance catalytic performance.

Lignocellulosic biomass is a promising renewable carbon carrier which could dramatically reduce our dependence on fossil resources; lignin is one of the important constituent of lignocellulosic biomasses in the form of cross-linked phenolic polymers ${ }^{8,10}$. Hydrodeoxygenation (HDO) is considered a critical reaction to upgrade pyrolysed lignin, known as bio-oil, to hydrocarbon fuels and 
high added-value chemicals (such as benzene, toluene and other aromatics) $)^{11,12}$. HDO reaction has typical heterogeneous catalytic features consisting of solid-phase catalyst, liquid-phase phenol substrate and gas-phase molecular hydrogen $\left(\mathrm{H}_{2}\right)$. In an attempt to enhance the performance of HDO reaction, intensive efforts have been devoted to design solid-phase catalysts with high efficiency for the cleavage of the $\mathrm{C}_{\text {aromatics }}-\mathrm{OH}$ bond because of its high dissociation enthalpy $\left(465 \mathrm{~kJ} \cdot \mathrm{mol}^{-1}\right)^{13-16}$.

Herein, we report the use of $\mathrm{N}_{2}$ to promote catalytic activity of HDO. In converting $p$-cresol to toluene (Scheme 1) over a ruthenium supported on titanium oxide catalyst $\left(\mathrm{Ru} / \mathrm{TiO}_{2}\right)$, we observed 4.3-fold activity increase at 160 degrees Celsius $\left({ }^{\circ} \mathrm{C}\right)$ and 1 bar $\mathrm{H}_{2}$ with additional 6 bar $\mathrm{N}_{2} . \mathrm{Ru} / \mathrm{TiO}_{2}$ was selected due to the strong hydrogenolysis and weak hydrogenation abilities of $\mathrm{Ru}^{17}$ and the $\mathrm{C}_{\text {aromatic }}-\mathrm{O}$ bond weakening ability of $\mathrm{TiO}_{2}$ with deoxygenation sites ${ }^{18} . P$-cresol was selected as the substrate because it is a good representative compound for the components found in lignin derived pyrolysis bio-oil ${ }^{16}$. Our detailed investigations indicate that $\mathrm{N}_{2}$ can be activated on Ru metallic surface to form hydrogenated nitrogen species $\left(\mathrm{N}_{2} \mathrm{H}_{\mathrm{x}}, \mathrm{x}=1-2\right)$ with $\mathrm{N}-\mathrm{H}$ bonds which may then offer a protic hydrogen to assist removal of - $\mathrm{OH}$ groups adsorbed on the catalyst surface, which may shift the ratedetermining-step of $\mathrm{HDO}$ of $p$-cresol from $-\mathrm{OH}$ hydrogenation $(1.63 \mathrm{eV})$ to $\mathrm{N}_{2}$ hydrogenation $(1.21 \mathrm{eV})$, and thus significantly decreasing the overall the activation energy of the HDO process. At the same time, $\mathrm{N}_{2}$ may also help removing the H-poisoned Ru surface so more metal sites can be available for HDO reaction. Furthermore, we find the $\mathrm{N}_{2}$ promotion effect was shown to be effective for a variety of $\mathrm{Ru}$ catalysts on different supports $\left(\mathrm{TiO}_{2}, \mathrm{Al}_{2} \mathrm{O}_{3}, \mathrm{ZrO}_{2}\right.$ and active carbon). Our results indicate that the incorporation of $\mathrm{N}_{2}$ during HDO could become a general approach for other highperformance HDO Ru-based catalysts.

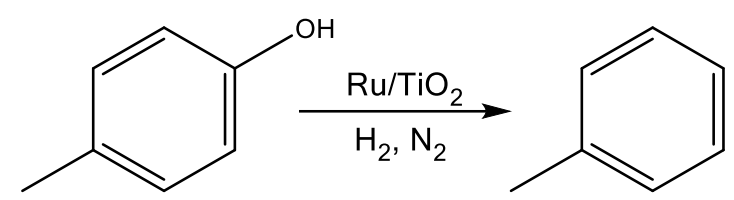

Scheme 1. Hydrodeoxygenation of $p$-cresol to toluene on $\mathbf{R u} / \mathbf{T i O}_{2} \cdot \mathrm{N}_{2}$ is used as a promoter.

\section{Results}

\section{Catalyst characterisation of $\mathrm{Ru} / \mathrm{TiO}_{2}$ catalyst}

$\mathrm{Ru} / \mathrm{TiO}_{2}$ catalyst was prepared using a wet-impregnation method (see Methods and Supplementary Fig. 1 for preparation). Aqueous solution of $\mathrm{RuCl}_{3}$ was impregnated into $\mathrm{TiO}_{2}$ with rapid stirring, drying and reduction in $\mathrm{H}_{2}$ at $400{ }^{\circ} \mathrm{C}$. High-angle annular dark-field scanning transmission electron microscopy (HAADF-STEM) images revealed that Ru particles were welldispersed on $\mathrm{TiO}_{2}$ support (Fig. 1a,b and Supplementary Fig. 2), with an average diameter of $1.2 \mathrm{~nm}$ (Fig. 1c). The composition of $\mathrm{Ru} / \mathrm{TiO}_{2}$ was shown by energy dispersive $\mathrm{X}$-ray spectroscopy (EDS) analysis in a STEM mode (Fig. 1d), and the loading amount of Ru was determined to be $0.74 \mathrm{wt} \%$ using inductively coupled plasma mass spectrometry (ICP-AES) analysis (Supplementary Table 1). 
Powder X-ray diffractogram (PXRD) data (Fig. 1e) revealed a mixed rutile and anatase phase of $\mathrm{TiO}_{2}$, and also showed weak Bragg reflections of Ru indicating that large crystalline Ru particles exist but in a small proportion, which was in consistent with the TEM results. The Lewis acidity of $\mathrm{Ru} / \mathrm{TiO}_{2}$ was confirmed (Supplementary Fig. 3), which is in consistent with the deoxygenation ability $\mathrm{TiO}_{2}{ }^{18}$.
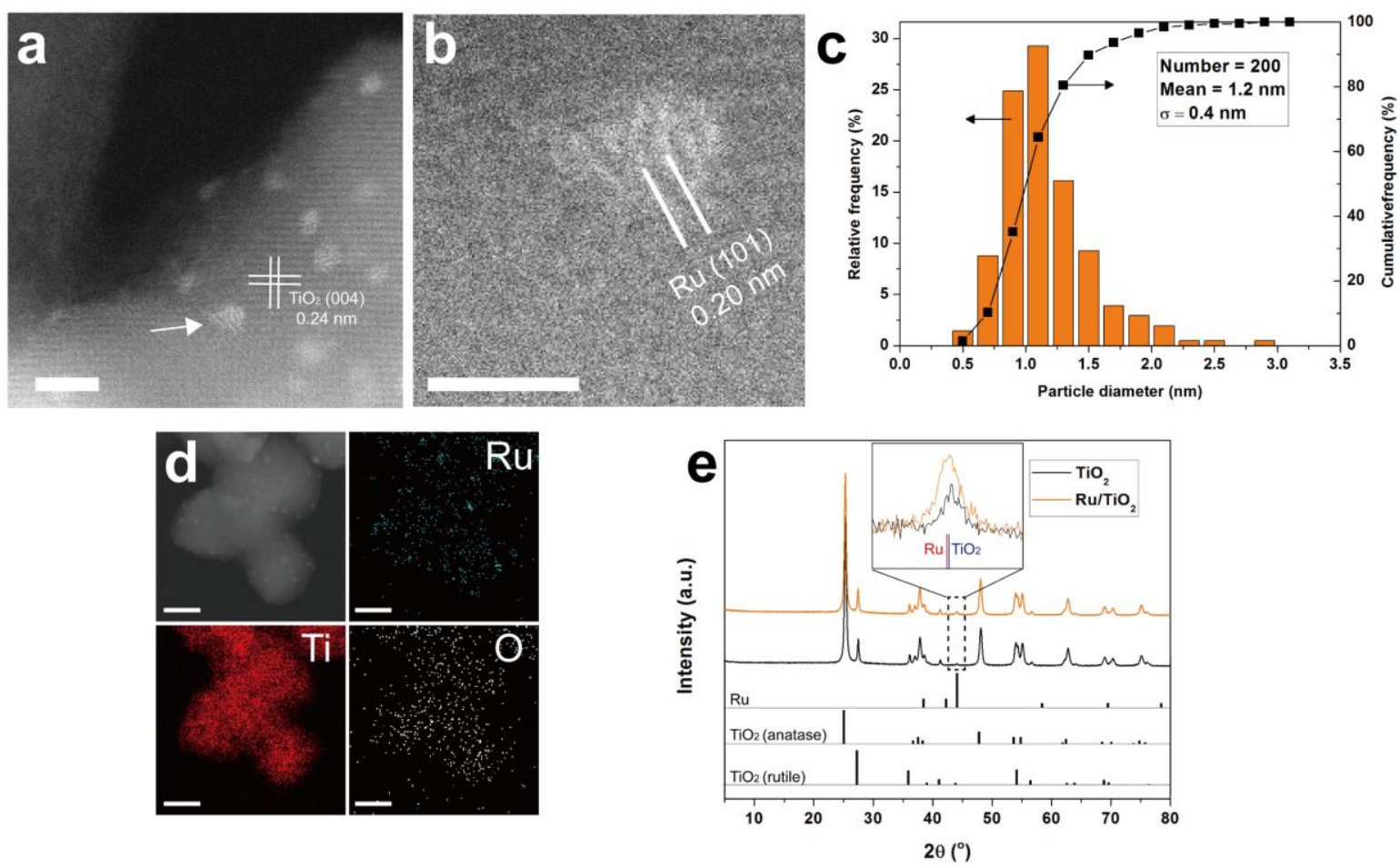

Fig. 1| Structure characterisations of the $\mathrm{Ru} / \mathrm{TiO}_{2}$ catalyst. High-angle annular dark-field scanning transmission electron microscopy images of $\mathbf{a}$, a representative region and $\mathbf{b}$, an individual particle of the $\mathrm{Ru} / \mathrm{TiO}_{2}$ catalyst shown with arrow in panel (a). Scale bar equals $2 \mathrm{~nm}$ in a, and equals $1 \mathrm{~nm}$ in $\mathrm{b}$. c, Size distribution of the Ru particles. d, STEM-EDS elemental mapping results for $\mathrm{Ru} / \mathrm{TiO}_{2}$. Scale bars equal $10 \mathrm{~nm}$. e, X-ray diffraction patterns of $\mathrm{Ru} / \mathrm{TiO}_{2}$ catalyst and $\mathrm{TiO}_{2}$. Inset highlights a specific region containing Ru diffraction peak.

\section{Catalytic performance of $\mathrm{Ru} / \mathrm{TiO}_{2}$ in the presence of $\mathrm{N}_{2}$}

The catalytic performance of $\mathrm{Ru} / \mathrm{TiO}_{2}$ was evaluated for the HDO of $p$-cresol in a batch reactor (details see Methods). Table 1 shows the comparison of catalytic performance of state-of-theart HDO catalysts and our catalyst for the conversion of $p$-cresol or other phenols to aromatics. As comparison to HDO results from the literature ${ }^{13,14,17}$, most Ru-based catalysts were studied at temperature higher than $200^{\circ} \mathrm{C}$ (entries 1-3 in Table 1). A higher activity was observed for isolated Co atoms doped onto $\mathrm{MoS}_{2}$ monolayers ${ }^{16}\left(\mathrm{Co}^{-}{ }^{\mathrm{S}} \mathrm{MoS}_{2}\right.$, entry 4), but the $\mathrm{H}_{2}$ pressure required was 30 bar. Although extremely mild condition was used on Ru catalysts modified by C,N-matrix (entry 5), alicyclic compounds rather than aromatics were the main products ${ }^{19,20}$. As seen in entry 6 , our $\mathrm{Ru} / \mathrm{TiO}_{2}$ catalyst showed similar toluene selectivity under similar temperature range and lower $\mathrm{H}_{2}$ 
pressure. Remarkably, if 6 bar $\mathrm{N}_{2}$ is added to the gas mixture as the complementary gas, the conversion increased as well as toluene selectivity (entry 7). We notice that $\mathrm{N}_{2}$ was used as a complementary gas in a previous study (entry 2$)^{21}$, but its catalytic effect was not studied. Considering that $\mathrm{N}_{2}$ is widely considered to be inert for HDO reaction, we have devoted significant efforts in trying to unravel the origin of the $\mathrm{N}_{2}$ promotion effect.

To identify catalytic trends inherent to the $\mathrm{Ru} / \mathrm{TiO}_{2}$ catalyst, HDO of $p$-cresol was conducted at low and constant conversion of $10 \%$ in a region free of external (Supplementary Fig. 4) and internal (Supplementary Note 1) mass transport limitations. As shown in the left columns in Fig. 2a (data in Supplementary Table 2), a 1.5-fold higher of toluene selectivity and 4.3-fold increase of $\mathrm{HDO}$ activity were observed in the presence of $\mathrm{N}_{2}$. The promoting effect of $\mathrm{N}_{2}$ in HDO reaction was also verified at another constant conversion of $21 \%$ (right two columns in Fig. 2a). Production of toluene follows a direct deoxygenation (DDO) pathway, with the formation of methylcyclohexane as over-hydrogenation product of toluene, and methylcyclohexanone and methylcyclohexanol as hydrogenation product of $p$-cresol (Supplementary Fig. 5), which is in agreement with previous report ${ }^{16}$.

Table 1| Comparison of HDO activity for the conversion of 4-methylphenol to toluene by using $\mathrm{Ru} / \mathrm{TiO}_{2}$ catalysts with/without $\mathrm{N}_{2}$ and state-of-the-art HDO catalysts from literature.

\begin{tabular}{|c|c|c|c|c|c|c|c|c|}
\hline Entry & Catalyst & $T\left({ }^{\circ} \mathrm{C}\right)$ & $\begin{array}{c}P(\text { bar }) \text { of } \\
\mathrm{H}_{2}\end{array}$ & $\begin{array}{c}P(\text { bar }) \text { of } \\
\text { additional gas }\end{array}$ & $t(\mathbf{h})$ & $\begin{array}{c}\text { Conversion } \\
(\%)\end{array}$ & $\begin{array}{c}\text { Toluene selectivity } \\
(\%)\end{array}$ & Ref. \\
\hline 1 & $\mathrm{Ru} / \mathrm{Nb}_{2} \mathrm{O}_{5}$ & 250 & 5 & - & 5 & 99.9 & 81.2 & 14 \\
\hline 2 & $\mathrm{Ru} / \mathrm{Zr}\left(\mathrm{SO}_{4}\right)_{2}$ & 240 & 2 & $6\left(\mathrm{~N}_{2}\right)$ & 2 & 99 & $99^{\mathrm{a}}$ & 13 \\
\hline 3 & $\mathrm{Ru}-\mathrm{WO}_{\mathrm{x}} / \mathrm{Si}-\mathrm{Al}$ & 220 & 10 & - & 1.5 & 100 & 83 & 17 \\
\hline 4 & $\mathrm{Co}-{ }^{\mathrm{S}} \mathrm{MoS}_{2}$ & 180 & 30 & - & 8 & 97.6 & 98.4 & 16 \\
\hline 5 & $\mathrm{Ru} / \mathrm{C}, \mathrm{N}$-matrix & 40 & 5 & - & 2 & 95 & $0^{\mathrm{d}}$ & 19 \\
\hline 6 & $\mathrm{Ru} / \mathrm{TiO}_{2}$ & 220 & 1 & $6(\mathrm{He})$ & 2 & 75.5 & 95.1 & This work \\
\hline 7 & $\mathrm{Ru} / \mathrm{TiO}_{2}$ & 220 & 1 & $6\left(\mathrm{~N}_{2}\right)$ & 2 & 97.4 & 98.4 & This work \\
\hline
\end{tabular}

$T$, temperature; $P$, pressure; $t$, time. Reaction conditions: batch reaction, $p$-cresol $(0.195 \mathrm{mmol}), \mathrm{Ru} / \mathrm{TiO}_{2}$ catalyst $(25 \mathrm{mg})$,

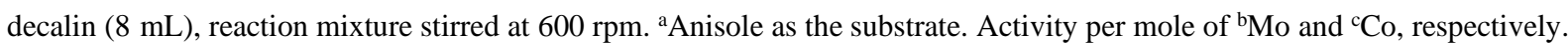
d99\% selectivity to cyclohexanol.

\section{Catalytic HDO in the presence of $\mathbf{N}_{2}$}

Before further experiments were carried out to understand the $\mathrm{N}_{2}$ promotion effect, the possibilities of oxidation of $\mathrm{Ru}$ and the presence of water was studied, due to the former one may be affecting the catalytic activity as well as the mechanism, and the latter one having been reported to promote $\mathrm{HDO}$ activity ${ }^{22}$. Firstly, two $\mathrm{Ru} / \mathrm{TiO}_{2}$ catalysts with different time of exposure to air (3 hours and 3 days) showed similar catalytic activity (Supplementary Fig. 6), suggesting that Ru with different degree of oxidation has little effect on the catalytic activity. The oxidised Ru species could 
be reduced during the course of the reaction, as demonstrated by temperature programmed reduction (TPR, Supplementary Fig. 7) and also by in situ X-ray photoelectron spectroscopy (XPS, Supplementary Fig. 8), which is in agreement with previous report ${ }^{23}$. To study the possibility that water promoted the HDO activity rather than $\mathrm{N}_{2}$ does, the catalytic reaction with a given amount of water was performed. No obvious difference on the catalytic activity was found (Supplementary Fig. 9), which is probably due to the nonpolar solvent (decalin) inhibiting the effect of water.

The promoting effect of $\mathrm{N}_{2}$ for $\mathrm{HDO}$ was investigated under varied $\mathrm{H}_{2}$ and $\mathrm{N}_{2}$ pressures. With increased $\mathrm{H}_{2}$ pressure, the toluene selectivity (Fig. 2b) as well as its yield (Supplementary Fig. 10) promoted by $\mathrm{N}_{2}$ became less pronounced. The reaction order for $\mathrm{H}_{2}$ of $\mathrm{Ru} / \mathrm{TiO}_{2}$ catalyst was measured to be -0.57 in the presence of $1-3$ bar $\mathrm{H}_{2}$ (Supplementary Fig. 11). The negative value could be attributed to hydrogen adatoms on the $\mathrm{Ru}$ surface via hydrogenolysis suppressed the adsorption of $\mathrm{N}_{2}$ and thus inhibited the $\mathrm{N}_{2}$ promoting effect, which is consistent with hydrogen poisoning effect observed in ammonia synthesis ${ }^{5}$. The preferential adsorption of $\mathrm{H}_{2}$ was also confirmed by the observation of higher selectivity for hydrogenation products under higher $\mathrm{H}_{2}$ pressure. With increased $\mathrm{N}_{2}$ pressure from $0-4$ bar, the conversion increased gradually and the toluene selectivity increased from 66.0 to $88.1 \%$ (Fig. 2c). It is known that the reaction order for $\mathrm{N}_{2}$ is between $0.8-1.0$ for ammonia synthesis over conventional Ru-loaded catalysts and is smaller for catalyst with stronger $\mathrm{N}_{2}$ dissociation ability ${ }^{5}$. In this work, the HDO reaction order for $\mathrm{N}_{2}$ was estimated in the range of 0.38 0.98 (Supplementary Fig. 12), although strictly it is inappropriate to call it 'HDO reaction order' because nitrogen is not incorporated in the reaction products. This result implies that $\mathrm{N}_{2}$ is activated on $\mathrm{Ru} / \mathrm{TiO}_{2}$ with the formation of active species that provide a lower activation barrier for the overall HDO reaction. The nature of the active species and proposed mechanism for the $\mathrm{N}_{2}$ activation is discussed later. Interestingly, the conversion and toluene selectivity start to decrease when the $\mathrm{N}_{2}$ pressure was further increased. Reaction rate is in the function of all surface species concentrations which include $\mathrm{N}_{2}, \mathrm{H}_{2}, p$-cresol and toluene. So the decrease in rate could be due to higher surface coverage of $\mathrm{N}_{2}$ over the $p$-cresol.

Besides $\mathrm{N}_{2}$ promotion effect in batch reaction, we have investigated the $\mathrm{N}_{2}$ promotion effect in a fixed-bed reaction. The reaction was carried out at constant total pressure ( 7 bar) and constant $\mathrm{H}_{2}$ partial pressures ( 1 bar), while the complementary gas was changed between 6 bar $\mathrm{N}_{2}$ and 6 bar $\mathrm{He}$ for three successive cycles. As shown in Fig. 2d, a higher toluene selectivity (i.e. 1.2-fold higher for the $1^{\text {st }}$ cycle) and conversion were observed in the presence of $\mathrm{N}_{2}$, while the selectivities of other products were not significantly changed. The fixed-bed reaction results showed the efficiency of $\mathrm{N}_{2}$ in promoting the HDO reaction. Although the catalytic results for batch and fixed-bed reactions are difficult to directly compare due to different kinetic factors applied (Supplementary Note 2), both of the reaction systems show higher toluene selectivity in the HDO of $p$-cresol with $\mathrm{N}_{2}$. The $\mathrm{Ru} / \mathrm{TiO}_{2}$ retained its particle size after reaction, as revealed by STEM imaging (Supplementary Fig. 13). A 
long-term stability test of the $\mathrm{N}_{2}$ promotion effect still remains to be investigated from an industrial perspective.
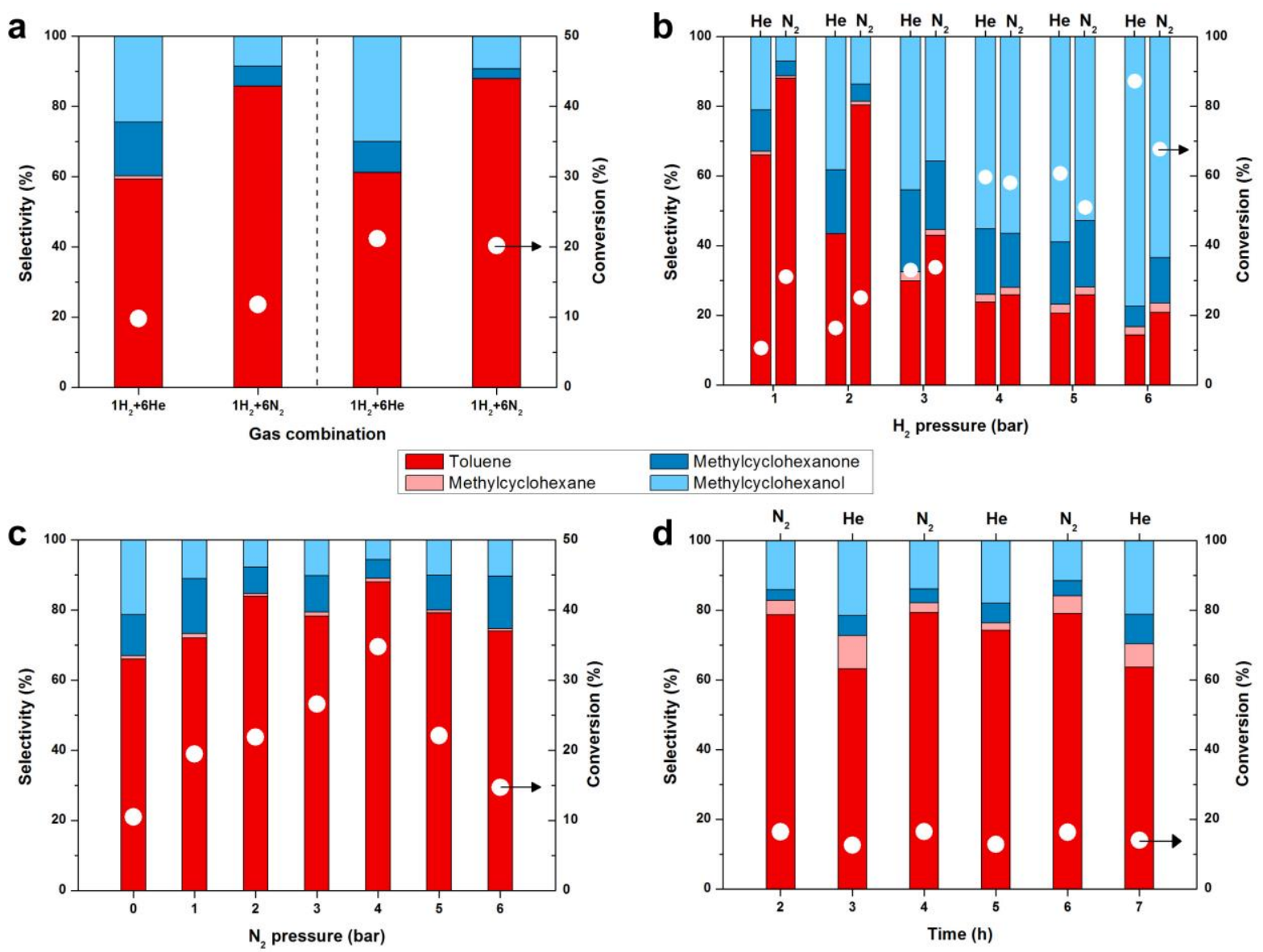

Fig. 2| Catalytic performance promoted by $\mathrm{N}_{2}$ in the hydrodeoxygenation of $p$-cresol using

$\mathbf{R u} / \mathrm{TiO}_{2}$ catalyst. Comparison of conversion and selectivity with or without $\mathrm{N}_{2}$ in batch reaction. a, Comparison at two different conversions, reaction conditions: a, $p$-cresol $(0.195 \mathrm{mmol}), \mathrm{Ru} / \mathrm{TiO}_{2}$ catalyst $\left(25,10,25,25 \mathrm{mg}\right.$ from left to right column), decalin $(8 \mathrm{~mL}), 160{ }^{\circ} \mathrm{C}$, reaction time $(1,1,4$, 1 hour from the left to right column), system pressure of 1 bar $\mathrm{H}_{2}$ and 6 bar $\mathrm{He}$ (or $1 \mathrm{bar}_{2}$ and 6 bar $\mathrm{N}_{2}$ ), mixture stirred at $600 \mathrm{rpm}$. b, Comparison at varied $\mathrm{H}_{2}$ pressures, reaction conditions: $p$-cresol (0.195 mmol), $\mathrm{Ru} / \mathrm{TiO}_{2}$ catalyst $(25 \mathrm{mg})$, decalin $(8 \mathrm{~mL}), 160{ }^{\circ} \mathrm{C}, 1$ hour, system pressure of 1-6 bar $\mathrm{H}_{2}$ and 6 bar $\mathrm{He}$ (or 1-6 bar $\mathrm{H}_{2}$ and 6 bar $\mathrm{N}_{2}$ ), mixture stirred at $600 \mathrm{rpm}$. c, Comparison at varied $\mathrm{N}_{2}$ pressures, reaction conditions: $p$-cresol $(0.195 \mathrm{mmol}), \mathrm{Ru} / \mathrm{TiO}_{2}$ catalyst $(25 \mathrm{mg})$, decalin $(8 \mathrm{~mL})$, $160{ }^{\circ} \mathrm{C}, 1$ hour, system pressure of 1 bar $\mathrm{H}_{2}, 6$ bar He and 0-6 bar $\mathrm{N}_{2}$, mixture stirred at $600 \mathrm{rpm}$. d, Comparison of conversion and selectivity with or without $\mathrm{N}_{2}$ in fixed-bed reaction. Reaction conditions: $p$-cresol (concentration of $1.12 \mathrm{mg} \cdot \mathrm{mL}^{-1}$ with decalin as solvent, flow rate of $0.2 \mathrm{~mL} \cdot \mathrm{min}^{-1}$ ), $\mathrm{Ru} / \mathrm{TiO}_{2}\left(100 \mathrm{mg}\right.$ ), $180^{\circ} \mathrm{C}$, system pressure of 1 bar $\mathrm{H}_{2}$ and 6 bar $\mathrm{He}$ (or 1 bar $\mathrm{H}_{2}$ and 6 bar $\mathrm{N}_{2}$ ), $\mathrm{H}_{2}$ flow rate of $5 \mathrm{~cm}^{3}(\mathrm{STP}) \mathrm{min}^{-1}, \mathrm{~N}_{2}$ (or He) flow rate of $30 \mathrm{~cm}^{3}(\mathrm{STP}) \mathrm{min}^{-1}$, weight hourly space velocity (WHSV, $0.134 \mathrm{~h}^{-1}$ ). 


\section{Understanding $\mathbf{N}_{2}$ promotion in catalytic $\mathrm{HDO}$}

In order to clarify the origin of the $\mathrm{N}_{2}$ promotion effect in catalytic $\mathrm{HDO}$, the kinetics of the $\mathrm{HDO}$ reaction with/without $\mathrm{N}_{2}$ was studied. The catalytic results were obtained at conversions below $20 \%$, the observed product distribution at this low conversion level could fingerprint the intrinsic reaction kinetics. Arrhenius plots were obtained based on the least squares linear fitting of $\ln$ (rate of toluene production) vs. 1,000/T (Fig. 3a). In the absence of $\mathrm{N}_{2}, \mathrm{Ru} / \mathrm{TiO}_{2}$ exhibited an apparent activation energy $\left(E_{\mathrm{a}}\right)$ value of $\sim 0.97 \mathrm{eV}$ for the $\mathrm{HDO}$ of $p$-cresol, in good agreement with the reported results ${ }^{24}$. Remarkably in the presence of $\mathrm{N}_{2}$, the $E_{a}$ was reduced significantly to $\sim 0.58 \mathrm{eV}$. This finding suggests that the adsorption of $\mathrm{N}_{2}$ with the formation of active species on $\mathrm{Ru} / \mathrm{TiO}_{2}$ decreases the activation energy and thus promotes the catalytic activity for HDO reaction.

To characterise the formation of active species from $\mathrm{N}_{2}$ adsorption, an on-line mass spectroscopy (MS) analysis for the effluent of reaction gas phase under fixed-bed reaction condition was implemented (for details see Methods). A $\mathrm{N}_{2} / \mathrm{H}_{2}$ mixture was flowed through a fixed-bed reactor packed with $\mathrm{Ru} / \mathrm{TiO}_{2}$ catalyst and the eluent was analysed by on-line mass spectrometry (MS). A number of species were detected at elevated temperatures, including $\mathrm{H}_{2}, \mathrm{~N}_{2}$, and possible hydrogenated nitrogen species including diimide $\left(\mathrm{N}_{2} \mathrm{H}_{2}\right)$, hydrazine $\left(\mathrm{N}_{2} \mathrm{H}_{4}\right)$ and ammonia $\left(\mathrm{NH}_{3}\right)$, with $\mathrm{m} / \mathrm{z}$ of $2,28,30,32$ and 17 , respectively. Among them, the only species showing increased intensity at elevated temperature was $\mathrm{m} / \mathrm{z}=30$ (Fig. 3c, Supplementary Fig. 14). Although generally considered to be unstable, it has been reported that the lifetime of $\mathrm{N}_{2} \mathrm{H}_{2}$ is long enough to be detected by $\mathrm{MS}^{25,26}$, thereby we tentatively identified the species with $\mathrm{m} / \mathrm{z}=30$ to it.

To study the formation of hydrogenated nitrogen species at high pressure with $\mathrm{N}_{2}$ and $\mathrm{H}_{2}$ atmosphere, in situ Fourier-transform infrared spectroscopy (FTIR) was carried out. As shown in Fig. 3c and 3d, the IR band at $3375 \mathrm{~cm}^{-1}$ and $3478 \mathrm{~cm}^{-1}$ are assigned to the $\mathrm{N}-\mathrm{H}$ and $=\mathrm{N}-\mathrm{H}$ species, respectively, and the primary IR band at $1623 \mathrm{~cm}^{-1}$ is attributed to the $\mathrm{N}=\mathrm{N}$ stretching mode of $\mathrm{N}_{2} \mathrm{H}_{\mathrm{x}}$ species, ${ }^{27}$ whereas no IR band was observed at atmosphere pressure (Supplementary Fig. 15). Moreover, the intensity of IR band $\left(\mathrm{N}=\mathrm{N}\right.$ at $\left.1623 \mathrm{~cm}^{-1}\right)$ increased gradually with an elevated temperature, which is consistent with the result from on-line MS measurements (Fig. 3b). It is generally accepted that the $\mathrm{O}-\mathrm{H}$ stretching vibration of surface hydroxyls is located at $1630 \mathrm{~cm}^{-1}$ to $1650 \mathrm{~cm}^{-1}$. In order to demonstrate that the IR band at $1623 \mathrm{~cm}^{-1}$ is not influenced by the surface hydroxyl species, only $\mathrm{H}_{2}$ was introduced into the in situ cell system after the sample was maintained at pressure of 7 bar ( 6 bar $\mathrm{N}_{2}$ and 1 bar $\mathrm{H}_{2}$ ) for $30 \mathrm{~min}$. As shown in Supplementary Fig. 16, the IR band at $1623 \mathrm{~cm}^{-1}$ assigned to $\mathrm{N}=\mathrm{N}$ double bond decreases gradually with the increment of time after introducing $\mathrm{H}_{2}$ atmosphere at pressure of 7 bar, whereas the bands at the region of 3600 to $3750 \mathrm{~cm}^{-1}$ show inconspicuous change, indicating that the IR band at $1623 \mathrm{~cm}^{-1}$ is not induced by the vibration of surface $\mathrm{O}-\mathrm{H}$ and can't be formed without $\mathrm{N}_{2}$. To further confirm that the IR band at $1623 \mathrm{~cm}^{-1}$ is attributed to the $\mathrm{N}_{2} \mathrm{H}_{\mathrm{x}}$ species, $\mathrm{N}_{2}$ isotope exchanged experiments were carried out under pressure of 7 bar with a stoichiometric $\mathrm{N}_{2}$ to $\mathrm{H}_{2}$ ratio of $6: 1$. As $\mathrm{N}_{2}$ was switched from ${ }^{14} \mathrm{~N}_{2}$ by ${ }^{15} \mathrm{~N}_{2}$, the 
characteristic IR band of ${ }^{14} \mathrm{~N}={ }^{14} \mathrm{~N}$ bond $\left(1623 \mathrm{~cm}^{-1}\right)$ shifts toward lower wavenumbers located at 1617 $\mathrm{cm}^{-1}$ attributed to the vibration of ${ }^{15} \mathrm{~N}={ }^{15} \mathrm{~N}$ bond (Supplementary Fig. 17.

To further study the formation of $\mathrm{N}_{2} \mathrm{H}_{\mathrm{x}}$ species adsorbed on the catalyst surface under reaction condition, in situ X-ray absorption near edge structure (XANES, Fig. 3e) measurements were carried out. The existence of nitrogen-containing species on the surface of $\mathrm{Ru} / \mathrm{TiO}_{2}$ under reaction conditions was shown by the presence of absorptions (centred at 398.1 and $401.0 \mathrm{eV}$ ) arising from transitions from the $\mathrm{K}$ shell $\left(\mathrm{N} \mathrm{1s}\right.$ ) to unoccupied $\pi^{*}$ orbital, and absorptions (centred at 405.5 and $413.0 \mathrm{eV}$ ) from the transition into $\sigma^{*}$ orbital $^{28}$. The intensities for the absorption peaks centred at 401.0, 405.5 and $413.0 \mathrm{eV}$ decrease with temperature, which were presumably associated with desorption of molecular $\mathrm{N}_{2}$ at increased temperature. In contrast, the absorption peak at $398.1 \mathrm{eV}$, which can be ascribed to the $=\mathrm{N}-$ group in $\mathrm{N}_{2} \mathrm{H}_{\mathrm{x}}$ species, exhibits an intensity enhancement with temperature. It indicates a dominance of an asymmetric species as $\mathrm{N}_{2} \mathrm{H}_{1}$, which is in good agreement with the following DFT calculation that $\mathrm{N}_{2} \mathrm{H}_{1}$ is kinetically more favourable to form on the $\mathrm{Ru} / \mathrm{TiO}_{2}$ surface than the symmetric species as $\mathrm{N}_{2} \mathrm{H}_{2}$.

In addition, it was reported that small molecules with amine groups such as ethylenediamine ${ }^{29}$ and 4-aminobenzylamine ${ }^{30}$ adsorbed on metal catalysts surface could influence the electronic structure of metal surface by electron donation and thus control the catalytic properties. To investigate if the formation of $\mathrm{N}_{2} \mathrm{H}_{\mathrm{x}}$ species changed the electron structure of Ru surface, in situ XPS measurements were conducted (Supplementary Fig. 18). The Ru photoemission features showed no shift after the adsorption of $\mathrm{N}_{2}$ under elevated temperature. A previous study ${ }^{31}$, also observed no change in the $\mathrm{Ru}$ chemical shifts following $\mathrm{N}_{2}$ adsorption, these studies indicate that the electronic structure of surface $\mathrm{Ru}$ was not influenced by $\mathrm{N}_{2} \mathrm{H}_{\mathrm{x}}$ species formation. The experimental data suggest that the role of $\mathrm{N}_{2} \mathrm{H}_{\mathrm{x}}$ species in promoting HDO is not mainly through tuning the electron structure of $\mathrm{Ru} / \mathrm{TiO}_{2}$ but possibly through chemical interaction with the reactants or intermediates during HDO. 

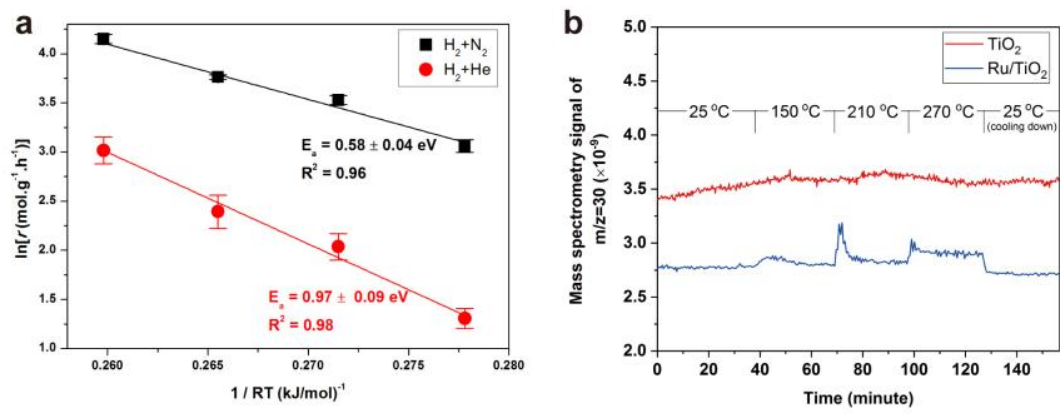

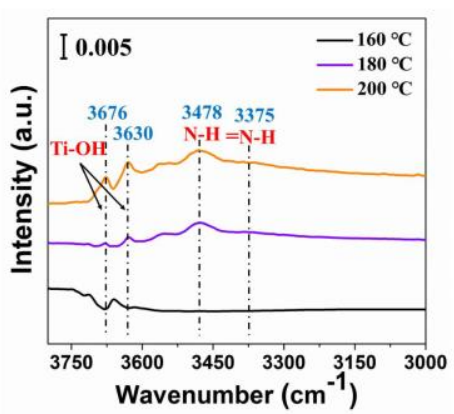

d

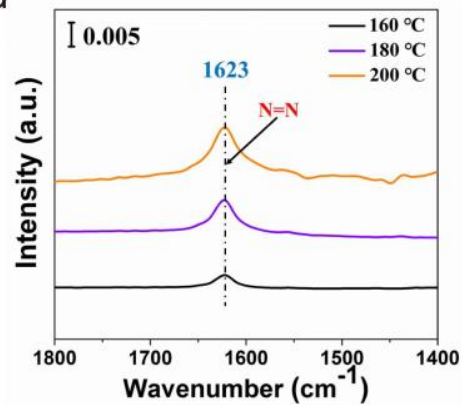

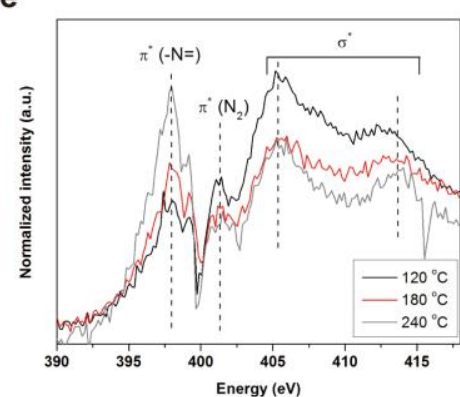

Fig 3| Understanding the promotion of $\mathbf{H D O}$ by $\mathbf{N}_{2}$. a, The Arrhenius plots of $\mathrm{Ru} / \mathrm{TiO}_{2}$ with/without $\mathrm{N}_{2}$. Reaction conditions: batch reaction, $p$-cresol $(0.195 \mathrm{mmol}), \mathrm{Ru} / \mathrm{TiO}_{2}(10 \mathrm{mg}), 160-$ $190{ }^{\circ} \mathrm{C}, 1$ bar $\mathrm{H}_{2}$ and 6 bar $\mathrm{He}$ (or 1 bar $\mathrm{H}_{2}$ and 6 bar $\mathrm{N}_{2}$ ), 1 hour, decalin $(8 \mathrm{~mL}$ ), mixture stirred at $600 \mathrm{rpm}$. Error bars represent standard deviation from three independent measurements. b, A fixedbed reaction with on-line mass spectroscopy fed with $\mathrm{H}_{2}$ and $\mathrm{N}_{2}$ at elevated temperatures, showing the presence of $\mathrm{N}_{2} \mathrm{H}_{2}(\mathrm{~m} / \mathrm{z}=30)$ over the $\mathrm{Ru} / \mathrm{TiO}_{2}$ catalyst. Reaction conditions: $\mathrm{Ru} / \mathrm{TiO}_{2}$ or $\mathrm{TiO}_{2}$ $(200 \mathrm{mg}), 5.6$ bar, velocity $\left(\mathrm{N}_{2}\right)=30 \mathrm{~cm}^{3}(\mathrm{STP})$ minutes $^{-1}$, velocity $\left(\mathrm{H}_{2}\right)=10 \mathrm{~cm}^{3}(\mathrm{STP})$ minutes $^{-1}$. In situ FTIR spectra over $\mathrm{Ru} / \mathrm{TiO}_{2}$ catalyst recorded in c, $3800-3000 \mathrm{~cm}^{-1}$ and $\mathbf{d}, 1800-1400 \mathrm{~cm}^{-1}$ at pressure of 7 bar with a stoichiometric $\mathrm{N}_{2}$ to $\mathrm{H}_{2}$ ratio of 6:1 at 160,180 and $200{ }^{\circ} \mathrm{C}$, respectively. e, in situ $\mathrm{N}$ XANES spectra of $\mathrm{Ru} / \mathrm{TiO}_{2}$ under exposure of mixture gas of $\mathrm{N}_{2} / \mathrm{H}_{2}(\mathrm{vol} / \mathrm{vol}=3 / 1)$ at 120,180 and $240{ }^{\circ} \mathrm{C}$.

\section{First principle calculations}

Density functional theory (DFT) calculations were performed in an effort to illustrate the role of $\mathrm{N}_{2}$ and deduce the possible reaction mechanism. A $\mathrm{Ru}_{19}$ cluster on an anatase $\mathrm{TiO}_{2}(101)$ slab was adopted as the computational model. A $\mathrm{Ru}_{19}$ moiety was selected due to it has two atomic layers $0.8 \mathrm{~nm}$ in diameter (Supplementary Fig. 19) ${ }^{32}$, which is a good model to represent the structure of $\mathrm{Ru} / \mathrm{TiO}_{2}$ observed from TEM image. An anatase $\mathrm{TiO}_{2}(101)$ was selected based on the structural results from XRD (Fig. 1e shows (101) peak at $2 \theta=25.3^{\circ}$ ) and from HAADF images, which was well studied ${ }^{33}$. Charge transfer from $\mathrm{Ru}_{19}$ cluster to $\mathrm{TiO}_{2}$ interface led to partial oxidation of the $\mathrm{Ru}$ atoms, the charge on the $\mathrm{Ru}_{19}$ cluster increases to +1.8 |e| based on Bader charge analysis, which promotes the $\pi$-d type adsorption of $p$-cresol to $-1.61 \mathrm{eV}$ upon the charge transfer with a strong metal-support 
interaction. Previous work demonstrated that on the surface of small Ru clusters $(<2 \mathrm{~nm})$ there was no so-called B5 site, where dissociative adsorption occurs ${ }^{34}$. As shown in Figs. 4a and $4 \mathbf{b}, \mathrm{N}_{2}$ dissociative barrier is as high as $1.48 \mathrm{eV}$ on $\mathrm{Ru}_{19}$ cluster, but the barrier for associative hydrogenation from $\mathrm{N}_{2}$ to $\mathrm{N}_{2} \mathrm{H}_{1}$ is only $0.79 \mathrm{eV}$, which is possible under these reaction conditions. This result agrees well with ${ }^{15} \mathrm{~N}_{2}$ isotope results, which shows that dissociation adsorption of $\mathrm{N}_{2}$ was not favourable over $\mathrm{Ru} / \mathrm{TiO}_{2}$ under reaction conditions (Supplementary Fig. 20). In addition, the adsorption by side-on way is important to activate $\mathrm{N}_{2}$ by back donation of electron from $3 \mathrm{~d}$ of metal to $\pi^{*}$ orbital of $\mathrm{N}_{2}$, which could reduce the bond order of triple bond of $\mathrm{N}_{2}{ }^{34}$. Further hydrogenation from $\mathrm{N}_{2} \mathrm{H}_{1}$ to $\mathrm{N}_{2} \mathrm{H}_{2}$ has a barrier of $1.21 \mathrm{eV}$ with an endothermic energy of $0.20 \mathrm{eV}$. Such endothermic process was also observed in other hydrogenation reaction ${ }^{34}$. The $\mathrm{N}-\mathrm{N}$ bond length is elongated from $1.24 \AA$ in $\mathrm{N}_{2} \mathrm{H}_{1}$ to $1.39 \AA$ in $\mathrm{N}_{2} \mathrm{H}_{2}$ and net charge of dinitrogen decreases from -1.88 to -2.69 |e|. For comparison, the pathway of hydrogenation from $\mathrm{N}_{2} \mathrm{H}_{1}$ to $\mathrm{N}_{2} \mathrm{H}_{2}$ is more difficult, with barrier of $1.91 \mathrm{eV}$. Further hydrogenation from $\mathrm{N}_{2} \mathrm{H}_{2}$ to $\mathrm{N}_{2} \mathrm{H}_{3}$ needs to overcome a barrier of $1.38 \mathrm{eV}$ with endothermic energy of $0.42 \mathrm{eV}$, which is harder under HDO reaction conditions (Supplementary Fig. 21). The theoretical results are consistent with the on-line MS study, where $\mathrm{N}_{2} \mathrm{H}_{4}$ or $\mathrm{NH}_{3}$ were not observed under reaction conditions. Thus, the calculations show that the reduction of $\mathrm{N}_{2}$ does not follow a dissociative pathway but an associative one, with the most possible product being $\mathrm{N}_{2} \mathrm{H}_{1}$, which is in good agreement with experimental results (Fig. 3c).

Formation of $\mathrm{N}-\mathrm{H}$ bonds in $\mathrm{N}_{2} \mathrm{H}_{\mathrm{x}}$ species provides new reaction pathway for $\mathrm{HDO}$ process in addition to simple hydrogenation with $\mathrm{H}_{2}$. We therefore can compare the reaction mechanism with and without $\mathrm{N}_{2} \mathrm{H}_{\mathrm{x}}$ species (Fig. 4c and Supplementary Fig. 22). On small Ru clusters, there are plentiful low-coordinated $\mathrm{Ru}$ atoms at the corner site of the clusters, where $p$-cresol binds with the $\mathrm{Ru}$ atoms by $\pi-\mathrm{d}$ donation with an adsorption energy $c a$. $-1.61 \mathrm{eV}$. The dissociation barrier for a $\mathrm{C}_{\text {aromatics }}-\mathrm{O}$ bond is $0.88 \mathrm{eV}$ with the $\mathrm{OH}$ group migrating to adjacent $\mathrm{Ru}$ site. Energy change for this step is about $-0.98 \mathrm{eV}$, so the formed $\mathrm{OH}$ group is relatively stable on the $\mathrm{Ru}$ cluster and is difficult to be removed by hydride $\left(\mathrm{H}^{\delta-}\right)$ atoms on $\mathrm{Ru}$, which is from $\mathrm{H}_{2}$ dissociative adsorption. The calculated barrier for $\mathrm{OH}+\mathrm{H} \rightarrow \mathrm{H}_{2} \mathrm{O}$ on $\mathrm{Ru}$ cluster is as high as $1.63 \mathrm{eV}$ because of unfavourable repulsion between the negatively charged $\mathrm{OH}$ groups $(-1.52|\mathrm{e}|)$ and hydride $(-0.26|\mathrm{e}|)$. For comparison in the step of $\mathrm{OH}$ group removing, when $\mathrm{N}_{2} \mathrm{H}_{2}$ is induced to this system, the $\mathrm{N}_{2} \mathrm{H}_{2}$ provides extra protic hydrogen $\left(\mathrm{H}^{\delta+}\right.$, Bader charge of $\left.+1.00|\mathrm{e}|\right)$ to eliminate the $\mathrm{OH}$ groups from the $\mathrm{Ru}$ surface by overcoming a much lower barrier of $0.41 \mathrm{eV}$. Finally, the $\mathrm{C}_{\text {aromatics }}$ obtained by capture of another $\mathrm{H}$ from the $\mathrm{Ru}$ surface forming toluene has a barrier of $0.68 \mathrm{eV}$. The rate-determining step (RDS) for the $\mathrm{HDO}$ process without $\mathrm{N}_{2}$ assistance is $\mathrm{OH}$ group hydrogenation with the barrier of $1.63 \mathrm{eV}$, whereas in the presence of $\mathrm{N}_{2}$ assistance and $\mathrm{N}_{2} \mathrm{H}_{2}$ formation the barrier for $\mathrm{OH}$ hydrogenation is decreased significantly, leading to $\mathrm{N}_{2}$ hydrogenation as the RDS. It worth mentioning that the formed $\mathrm{N}_{2} \mathrm{H}_{2}$ is able to reversely convert to $\mathrm{N}_{2}$ and $\mathrm{H}_{2}$ on $\mathrm{Ru}$ surface due to the low $\mathrm{E}_{\mathrm{a}}$ with equilibrium being 
established. In the presence of $\mathrm{HDO}$, it is plausible that the produced $\mathrm{N}_{2} \mathrm{H}_{2}$ could be largely consumed, which renders the promotion of $\mathrm{N}_{2} \mathrm{H}_{2}$ formation. Besides $\mathrm{N}_{2} \mathrm{H}_{2}, \mathrm{~N}_{2} \mathrm{H}_{1}$ could also be responsible for removing surface $\mathrm{OH}$, This reaction, $\mathrm{OH}+\mathrm{NNH} \rightarrow \mathrm{H}_{2} \mathrm{O}+\mathrm{N}_{2}$, also has a low barrier of $0.42 \mathrm{eV}$ and a exothermic reaction energy of $-0.04 \mathrm{eV}$, which is very similar with the $\mathrm{N}_{2} \mathrm{H}_{2}$ pathway. Note that at $\mathrm{Ru} / \mathrm{TiO}_{2}$ interface, $\mathrm{H}_{2} \mathrm{O}$ and $\mathrm{OH}$ group could also accelerate the $\mathrm{C}-\mathrm{OH}$ dissociation. The activation barrier is only $0.33 \mathrm{eV}$, but regeneration of such interface $\mathrm{H}_{2} \mathrm{O}$ is a strong endothermic step of about $0.96 \mathrm{eV}$ (Supplementary Table. 3), which is similar to the reported data ${ }^{24}$. We also considered the migration of $\mathrm{OH}$ group from $\mathrm{Ru}$ to $\mathrm{TiO}_{2}$, The calculated $\mathrm{OH}$ diffusion barrier from $\mathrm{Ru}$ to bare $\mathrm{Ti}$ site at interface is only about $0.60 \mathrm{eV}$, but the regeneration of interface Ti site by $\mathrm{H}_{2} \mathrm{O}$ formation need to overcome a much higher barrier of about $1.41 \mathrm{eV}$ (Supplementary Fig. 23). The original activity without $\mathrm{N}_{2}$ could be attributed to the interface reactions. In summary, the origin of the $\mathrm{N}_{2}$ promotion effect for HDO activity is proposed in Fig. $4 \mathbf{c}$, in which $\mathrm{N}_{2} \mathrm{H}_{\mathrm{x}}$ species are produced by $\mathrm{N}_{2}$ activation (left part in Fig. 4c) which provides protic hydrogen to hydrodeoxygenate $p$-cresol (right part in Fig. $4 c)$.

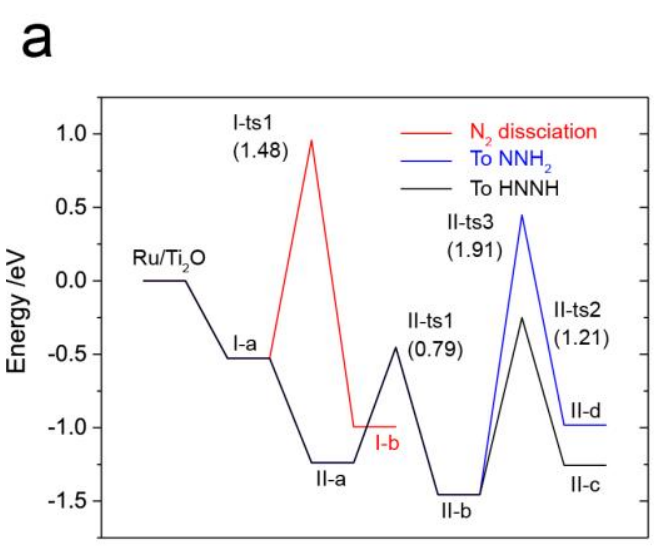

b
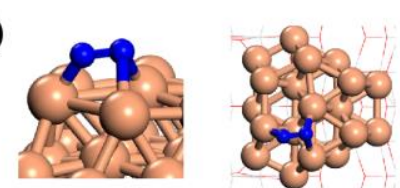
l-a(Side view)
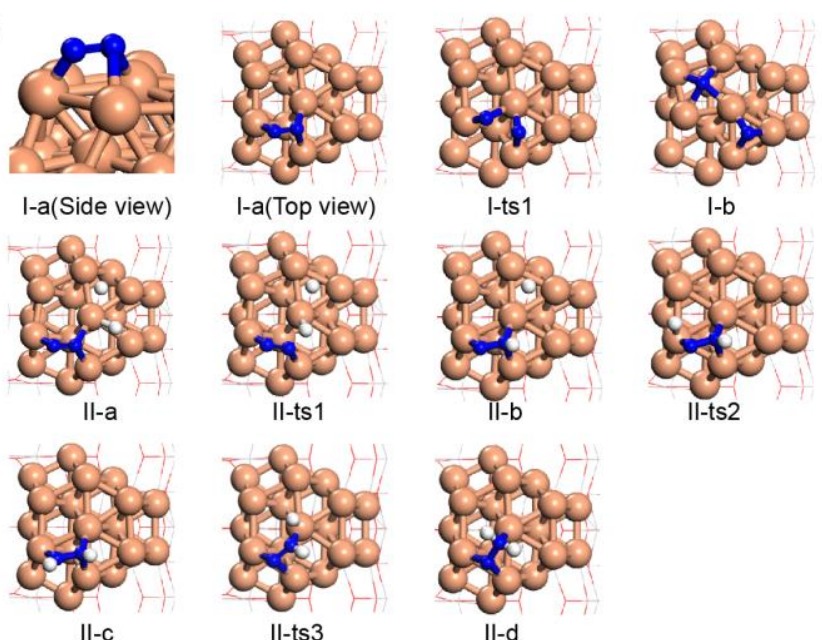

C

II-C

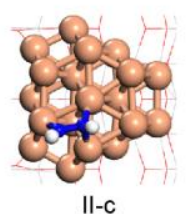

step 1, $\mathrm{C}-\mathrm{OH}$ cleavage:
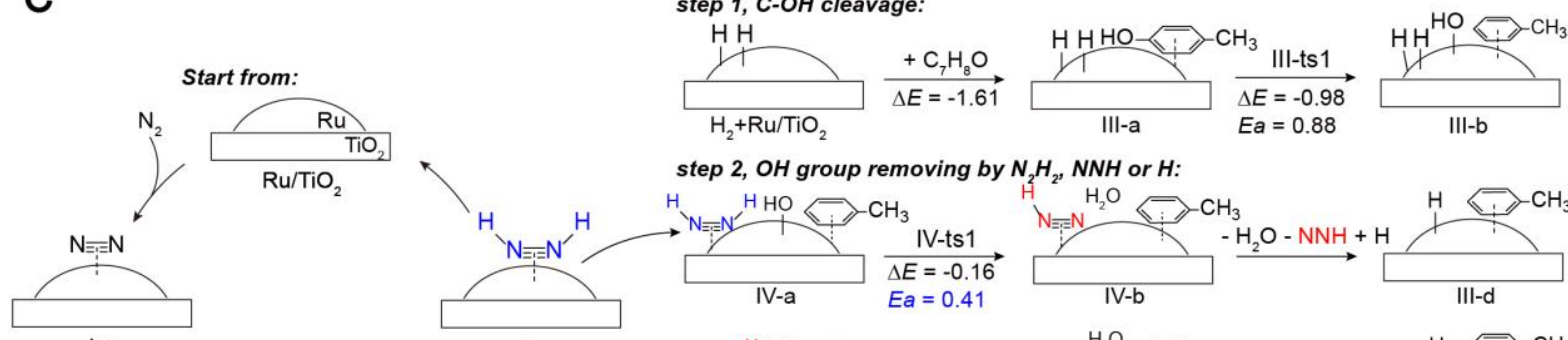

$\mathrm{N}_{2} \mathrm{H}_{2}, \mathrm{NNH}$ or $\mathrm{H}$ :
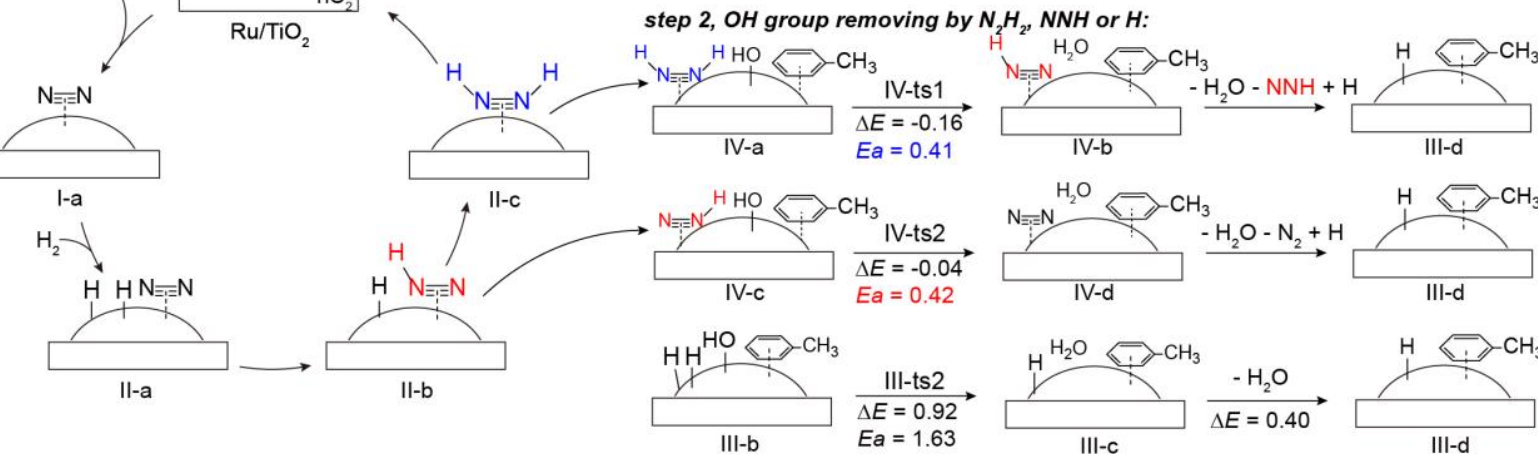

step 3, Toluene formation:
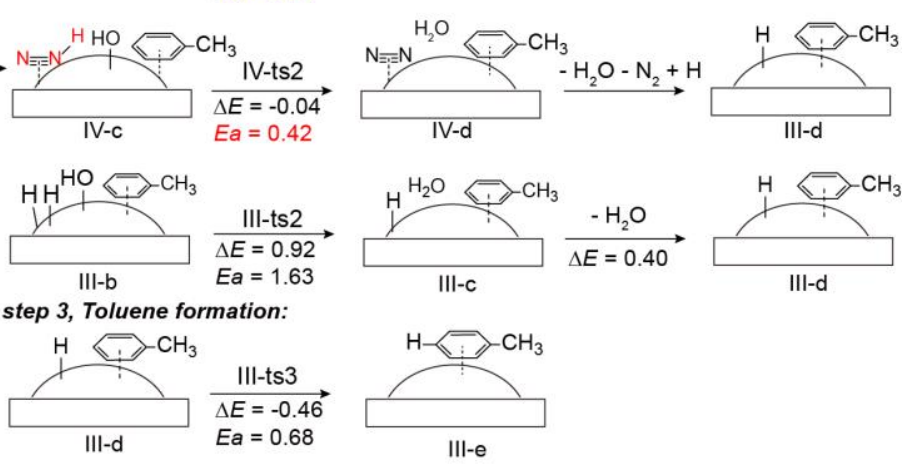
Fig 4| DFT results of the reaction mechanism. a, b, Reaction energy profiles and its corresponding structures of $\mathrm{N}_{2}$ dissociation (red curve) and hydrogenation on $\mathrm{Ru}_{19} / \mathrm{TiO}_{2}$ (black curve). c, Illustration of the proposed reaction mechanism combining of $\mathrm{N}_{2}$ activation and HDO reaction. Colour code of the spheres: Ru (light orange), Ti (light grey), $\mathrm{O}$ (red), $\mathrm{N}$ (blue), $\mathrm{C}$ (dark grey) and $\mathrm{H}$ (white).

\section{Discussion}

We have investigated if $\mathrm{N}_{2}$ promotion effect is a generalised phenomenon for other Ru-based catalysts with different supports $\left(\mathrm{Ru} / \mathrm{TiO}_{2}, \mathrm{Ru} / \mathrm{Al}_{2} \mathrm{O}_{3}, \mathrm{Ru} / \mathrm{ZrO}_{2}\right.$ and $\left.\mathrm{Ru} / \mathrm{C}\right)$. All the catalysts were synthesised by wet-impregnation method (see Method) except $\mathrm{Ru} / \mathrm{C}$ which was supplied by Alfa Aesar. The weight loading of Ru was determined by ICP-AES analysis (Supplementary Table 1) and $\mathrm{Ru}$ particles were formed in nano size regime (Supplementary Fig. 24). Increase in HDO activity in the presence of $\mathrm{N}_{2}$ was observed over these catalysts with varied supports (Supplementary Fig. 25), in which $\mathrm{TiO}_{2}$ exhibited a higher selectivity and conversion promoted by $\mathrm{N}_{2}$.

Our experimental and theoretical studies show that associative $\mathrm{N}_{2}$ reduction through reaction with $\mathrm{H}$-containing species provide $\mathrm{N}_{2} \mathrm{H}_{\mathrm{x}}$ species which help to promote the p-cresol to toluene conversion over a series of $\mathrm{Ru}$ supported on various metal oxides or carbon catalysts. Associative reduction of $\mathrm{N}_{2}$ was also demonstrated on other supported small metal clusters and is effective under mild conditions ${ }^{35,36}$. The preferred mechanism is an associative pathway of $\mathrm{N}_{2}$ reduction rather than the dissociative pathway is reminiscent of the activation of $\mathrm{O}_{2}$, where the facile formation of $\mathrm{OOH}$ via an associative pathway plays a critical role ${ }^{37,38}$. This low-barrier associative pathway for $\mathrm{N}_{2}$ reduction may explain why the inert $\mathrm{N}_{2}$ can have such an unexpected promotion role. In addition, the competition for same Ru site between $\mathrm{H}, \mathrm{N}_{2}, p$-cresol and toluene may also exist under the reaction condition and make contribution to the activity enhancement in the presence of $\mathrm{N}_{2}$. $\mathrm{H}$ poisoning is commonly taken place on Ru over $200{ }^{\circ} \mathrm{C}^{5}$, and any surface species, for example $\mathrm{N}_{2}$ in our case, that can remove $\mathrm{H}$ and vacant the $\mathrm{Ru}$ site will facilitate faster adsorption of $p$-cresol hence higher rate.

\section{Conclusion}

We have discovered an efficient strategy for promoting HDO activity by introducing $\mathrm{N}_{2}$ into the HDO reaction. Experimental and theoretical calculations suggest that $\mathrm{N}_{2}$ may be converted to $\mathrm{N}_{2} \mathrm{H}_{\mathrm{x}}$ species, which provide protic hydrogen to assist hydrogenation of hydroxyl on $p$-cresol with lower activation energy than direct deoxygenation by $\mathrm{H}_{2}$. The key steps of the proposed mechanism are illustrated in Scheme 2, highlighting the combination of $\mathrm{N}_{2}$ activation and HDO reaction via $\mathrm{N}_{2}$. At the same time, $\mathrm{N}_{2}$ may remove $\mathrm{H}$, vacant the $\mathrm{Ru}$ site and facilitate faster adsorption of $p$-cresol hence higher rate. Our data suggest that $\mathrm{N}_{2}$ should no longer be considered as a simple inert carrier gas. 


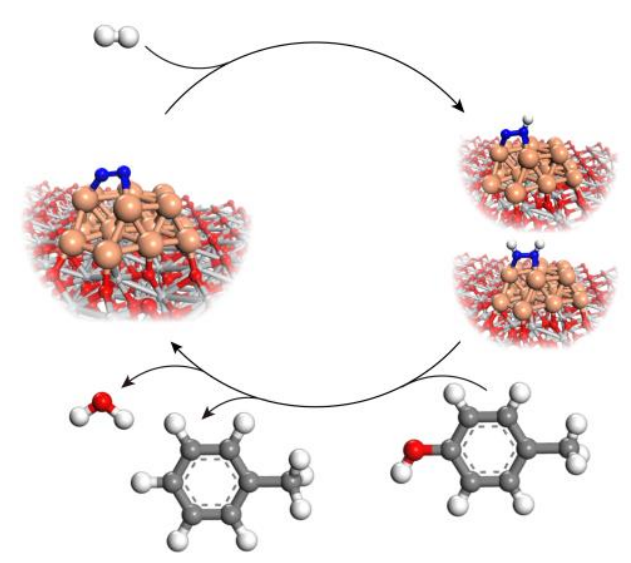

Scheme 2. Illustration of combination of $\mathrm{N}_{2}$ activation and $\mathrm{HDO}$ reaction over $\mathrm{Ru} / \mathrm{TiO}_{2} \cdot \mathrm{N}_{2}$ was catalysed to $\mathrm{NNH}$ and $\mathrm{HNNH}$ over $\mathrm{Ru} / \mathrm{TiO}_{2}$, offering protic hydrogen for converting $p$-cresol to toluene over the same catalyst. Colour code of the spheres: Ru (light orange), Ti (light grey), O (red), $\mathrm{N}$ (blue), $\mathrm{C}$ (dark grey) and $\mathrm{H}$ (white).

\section{Methods}

\section{Sample preparation}

For the synthesis of $\mathrm{Ru} / \mathrm{TiO}_{2}$ catalyst, $\mathrm{RuCl}_{3}(0.03 \mathrm{mmol})$ was dissolved in $3 \mathrm{~mL}$ de-ionised water. The mixture was stirred for $1 \mathrm{~h}$ and then added dropwise to $\mathrm{TiO}_{2}(0.24 \mathrm{~g})$. In the wet-impregnation method for preparing the catalyst, the water volume we used was larger than that needed to saturate the $\mathrm{TiO}_{2}$ surface, so suspension liquid (Supplementary Fig. 1) rather than glue-like sample was formed. The formation of the suspension liquid allows to be stirred vigorously for 2 hours and then the sample was dried overnight in an oven at $120{ }^{\circ} \mathrm{C}$ and then reduced in $\mathrm{H}_{2}$, at a flow rate of 20 $\mathrm{cm}^{3} / \mathrm{min}$ and a heating rate of $2{ }^{\circ} \mathrm{C} / \mathrm{min}$ to $400{ }^{\circ} \mathrm{C}$, with the target temperature held for 3 hours. The sample was subsequently cooled down to room temperature and protected with $\mathrm{N}_{2}$ for $1 \mathrm{~h}$ prior to removal from the tube reactor for catalytic reactions or other tests. For the synthesis of other Ru catalysts, including $\mathrm{Ru} / \mathrm{Al}_{2} \mathrm{O}_{3}$ and $\mathrm{Ru} / \mathrm{ZrO}_{2}$, the synthetic recipes are similar expect the support. $\mathrm{RuCl}_{3}$, $\mathrm{Ru} / \mathrm{C}, \mathrm{TiO}_{2}, \mathrm{Al}_{2} \mathrm{O}_{3}$ and $\mathrm{ZrO}_{2}$ were purchased from Sigma-Aldrich.

\section{High-angle annular dark-field scanning transmission electron microscopy}

An aberration-corrected JEOL ARM300 CF operated at $300 \mathrm{kV}$ in STEM mode was used for microstructure characterisation. The convergence angle of the probe was $26 \mathrm{mrad}$ [if $30 \mathrm{um}$ aperture used] with imaging performed at $9 \mathrm{~cm}$ camera length. With this configuration, we collected the scattered electrons between 77 to $210 \mathrm{mrad}$ (annual dark-field - ADF- signal) and 13 to $28 \mathrm{mrad}$ (annular bright field - ABF- signal). Energy-dispersive X-ray elemental maps and spectra were collected using a window-less Oxford Instruments XMAX 100 TLE silicon drift detector. For STEM 
imaging, the probe current used was around $25 \mathrm{pA}$. The probe current was increased to around $500 \mathrm{pA}$ for EDX elemental mapping.

\section{Powder X-ray Diffraction}

Powder X-ray Diffraction (PXRD) data were obtained on a PANAnalytical X'Pert Pro diffractometer in reflection mode at $40 \mathrm{kV}$ and $40 \mathrm{~mA}$ using $\mathrm{Cu} \mathrm{K \alpha}$ radiation.

\section{Fourier-transform infrared spectra of pyridine adsorption}

Fourier transform infrared (FTIR) spectra of pyridine adsorption were collected on the Bruker Tensor 27 spectrometer. A self-supporting pellet made of $200 \mathrm{mg}\left(20 \mathrm{wt} \%\right.$ of $\mathrm{Ru} / \mathrm{TiO}_{2}$ was mixed with $\mathrm{KBr}$ ) sample was placed in the flow cell and evacuated at $673 \mathrm{~K}$ for $2 \mathrm{~h}$. After the sample temperature was cooled down to $150^{\circ} \mathrm{C}$, the background spectrum of the sample was recorded. Pyridine vapour was adsorbed on the sample for 30 minutes at $150{ }^{\circ} \mathrm{C}$ followed by desorption at $150,175,200$ and $250{ }^{\circ} \mathrm{C}$ for 30 minutes, respectively, and the spectra of the sample were recorded in between each temperature ramp. The spectral bands at 1605 and $1450 \mathrm{~cm}^{-1}$ were used to identify Lewis acid site.

\section{Catalysis testing in batch reaction}

Using the hydrodeoxygenation of $p$-cresol over $\mathrm{Ru} / \mathrm{TiO}_{2}$ with $\mathrm{N}_{2}$ incorporation as an example, we loaded $p$-cresol $(0.195 \mathrm{mmol})$ into a stainless steel Parr autoclave (reactor volume, $50 \mathrm{~mL}$ ) with decalin $(8 \mathrm{~mL})$ and $\mathrm{Ru} / \mathrm{TiO}_{2}(2.5-50 \mathrm{mg})$. After the autoclave was sealed, it was cleaned with $\mathrm{N}_{2}$ for three times, purged 6 bar $\mathrm{N}_{2}$ and then 1 bar $\mathrm{H}_{2}$ at room temperature. The reaction was carried out at $60-240{ }^{\circ} \mathrm{C}$ for $1-24 \mathrm{~h}$ with a stirring speed of $600 \mathrm{rpm}$. After the reaction was completed and cooled down to room temperature, the products were collected and was qualitatively analysed by gas chromatograph-mass spectrometry (GC-MS) and quantitatively analysed by a flame ionisation detector (GC-FID) using external standard method. The gases composition and pressure maybe changed depending on the reaction.

\section{Catalysis testing in fixed-bed reaction}

The reactions were performed on a HEL made continuous trickle bed reactor (mode FlowCAT), connected with on-line mass spectroscopy. The $\mathrm{Ru} / \mathrm{TiO}_{2}$ catalyst $(100 \mathrm{mg}$ ) was located in the middle 
of the tubular reactor with quartz wool plugs on both the sides. Liquid feed ( $p$-cresol dissolved in decalin with concentration of $1.12 \mathrm{mg} \cdot \mathrm{mL}^{-1}$ ) was fed by using a HPLC pump with constant flow rate of $0.2 \mathrm{~mL} \cdot \mathrm{min}^{-1}$. The $\mathrm{N}_{2}$ and $\mathrm{H}_{2}$ mixing gases or $\mathrm{H}_{2}$ gas were alternatively passed in downward direction with velocity controlled by mass-flow controllers, with the $\mathrm{N}_{2}$ and $\mathrm{H}_{2}$ flow rates of 10 and $30 \mathrm{~cm}^{3}(\mathrm{STP})$ minutes $^{-1}$, respectively, and total pressure of 8 bar mixing gas $\left(2\right.$ bar $\mathrm{H}_{2}+6$ bar $\left.\mathrm{N}_{2}\right)$ or 2 bar $\mathrm{H}_{2}$, respectively. The flow rates are respectively calibrated by using a soap film bubble flowmeter. Weight hourly space velocity was maintained at $0.134 \mathrm{~h}^{-1}$. The reaction was carried out at $180{ }^{\circ} \mathrm{C}$. The products were collected and were qualitatively analysed by GC-MS and quantitatively analysed by GC-FID using external standard method.

\section{Gas chromatograph-mass spectrometry analysis}

GC-MS and GC-FID analysis was conducted simultaneously by using an Agilent gas chromatograph equipped with an Agilent 19091N-133 column of mode HP-INNOWax with high polarity, $30 \mathrm{~m} * 250 \mu \mathrm{m} * 0.25 \mu \mathrm{m}$ connected column splitter which connects to mass spectrometer and FID. The GC oven was programmed as: hold at initial temperature of $313 \mathrm{~K}$ for 5 minutes, ramp at $15 \mathrm{~K}$ minutes $^{-1}$ to $523 \mathrm{~K}$ and hold at $523 \mathrm{~K}$ for 5 minutes. The peaks were analysed by comparing the corresponding spectra with those of the NIST 2011 MS library.

\section{X-ray photoelectron spectroscopy measurements}

XPS measurements for investigation of oxidation degree of $\mathrm{Ru} / \mathrm{TiO}_{2}$ and its reduction ability at increased temperature were performed using Axis Ultra Imaging Photoelectron Spectrometer (Kratos Analytical Ltd.). The $\mathrm{Ru} / \mathrm{TiO}_{2}$ catalyst was made into a small tablet ( $6.0 \mathrm{~mm}$ diameter) and held on the sample holder. The tablet of catalyst was reduced in $\mathrm{H}_{2}$ in the pre-treatment chamber of the XPS spectrometer at $100,160,220^{\circ} \mathrm{C}$, respectively, for $0.5 \mathrm{~h}$. The sample was then introduced into the UHV chamber for XPS measurement at room temperature. XPS measurements for study of $\mathrm{N}_{2} / \mathrm{H}_{2}$ mixture gas adsorption on $\mathrm{Ru} / \mathrm{TiO}_{2}$ at increased temperature were performed at the photoemission end-station at beamline BL10B in the National Synchrotron Radiation Laboratory (NSRL) in Hefei, China. Briefly, the beamline is connected to a bending magnet and covers photon energies from 100 to $1000 \mathrm{eV}$ with a resolving power $(\mathrm{E} / \Delta \mathrm{E})$ better than 1000 . The end-station is composed of four chambers, i.e., analysis chamber, preparation chamber, quick sample load-lock chamber and high pressure reactor. The analysis chamber, with a base pressure of $<5 \times 10^{-10}$ torr, is connected to the beamline and equipped with a VG Scienta R3000 electron energy analyser and a twin anode X-ray source. The high pressure reactor houses a reaction cell where the samples can be treated with different gases up to $20 \mathrm{bar}$ and simultaneously heated up to $650{ }^{\circ} \mathrm{C}$. After the sample treatment, the 
reactor can be pumped down to high vacuum $\left(<10^{-8}\right.$ torr $)$ for sample transfer. In the current work, the sample was treated with $\mathrm{H}_{2}$ at $400{ }^{\circ} \mathrm{C}$ for 3 hours in the high pressure reactor and then treated with a mixture gas of $\mathrm{N}_{2} / \mathrm{H}_{2}(\mathrm{vol} / \mathrm{vol}=3 / 1)$ at 120,180 and $240{ }^{\circ} \mathrm{C}$ for 1 hour, respectively, after which it was transferred to analysis chamber for XPS measurement without exposing to air.

\section{On-line mass spectroscopy measurements}

Identification of formation of nitrogen-involved intermediate was performed on a HEL made continuous trickle bed reactor (mode FlowCAT), connected with on-line mass spectroscopy. The $\mathrm{Ru} / \mathrm{TiO}_{2}$ catalyst $(200 \mathrm{mg}$ ) was located in the middle of the tubular reactor with quartz wool plugs on both the sides. The ${ }^{14} \mathrm{~N}_{2}$ and $\mathrm{H}_{2}$ gases were passed in downward direction with velocity controlled by mass-flow controllers, with the ${ }^{14} \mathrm{~N}_{2}$ and $\mathrm{H}_{2}$ flow rates of 10 and $30 \mathrm{~cm}^{3}$ (STP)minutes ${ }^{-1}$, respectively, and total pressure of 5.6 bar. The flow rates are respectively calibrated by using a soap film bubble flowmeter. The reaction temperature was elevated from 25 to 150,210 and $270{ }^{\circ} \mathrm{C}$ and stabilised at each temperature for $30 \mathrm{~min}$, and then back to $25^{\circ} \mathrm{C}$. The effluent of the gas was separated into two streams: the main stream was passing to a back pressure regulator which controlled the pressure, and the side stream was passing to a mass spectroscopy (MS) with the stream volume carefully controlled by a needle valve to ensure the reactor pressure was maintained at set value. The MS mode is HPR-20 QIC Benchtop Gas Analysis System. The MS testing mode is Multiple Ion Detection (MID) mode. Mass fragments of $\mathrm{m} / \mathrm{z}=17\left(\mathrm{NH}_{3}\right), 28\left(\mathrm{~N}_{2}\right), 30\left(\mathrm{~N}_{2} \mathrm{H}_{2}\right)$ and $32\left(\mathrm{~N}_{2} \mathrm{H}_{4}\right)$ were monitored at the same time.

\section{In situ Fourier-transform infrared spectroscopy measurements}

In situ Fourier-transform infrared spectroscopy (FTIR) were carried out in a modified in situ transmission reaction cell on a VERTEX 70 spectrometer equipped with a MCT narrow-band detector, with a resolution of $4 \mathrm{~cm}^{-1}$. The experiments were carried out over $\mathrm{Ru} / \mathrm{TiO}_{2}$ catalyst at with a stoichiometric $\mathrm{N}_{2}$ to $\mathrm{H}_{2}$ ratio of $6: 1$ with flow rate of $30 \mathrm{ml} / \mathrm{min}$ at different temperature and pressure. In a typical process, the fresh powered $\mathrm{Ru} / \mathrm{TiO}_{2}$ sample with $20 \mathrm{mg}$ were pressed into sheet and activated in $10 \% \mathrm{H}_{2} / \mathrm{He}$ at $200{ }^{\circ} \mathrm{C}$ for $30 \mathrm{~min}$. When the temperature was cooled to $160{ }^{\circ} \mathrm{C}$, a mixed gas with a stoichiometric $\mathrm{N}_{2}$ to $\mathrm{H}_{2}$ ratio of $6: 1$ with a flow of $30 \mathrm{ml} / \mathrm{min}$ was introduced into the reactor, and the pressure was increased to 7 bar. After the reaction equilibrium for $30 \mathrm{~min}$, in situ FTIR spectra were recorded in (a) $3800-3000 \mathrm{~cm}^{-1}$ and (b) $1800-1400 \mathrm{~cm}^{-1}$. For the $\mathrm{H}_{2}$ treating experiment, after the reaction equilibrium for $30 \mathrm{~min}, 10 \% \mathrm{H}_{2} / \mathrm{He}$ was introduced into the reactor with flow rate of $30 \mathrm{ml} / \mathrm{min}$. For the $\mathrm{N}_{2}$ isotope exchanged experiment, after the reaction equilibrium for $30 \mathrm{~min},{ }^{15} \mathrm{~N}_{2}$ and $\mathrm{H}_{2}$ was introduced into the reactor with flow rate of 30 and $5 \mathrm{ml} / \mathrm{min}$, respectively. 


\section{In situ X-ray absorption near edge structure measurements}

In situ $\mathrm{N}$ K-edge XANES spectra for $\mathrm{N}_{2} / \mathrm{H}_{2}$ mixture gas adsorption at increased temperature were measured at the photoemission end-station at beamline BL10B in the National Synchrotron Radiation Laboratory (NSRL) in Hefei, China. A bending magnet is connected to the beamline, which is equipped with three gratings covering photon energies from 100 to $1000 \mathrm{eV}$. In this experiment, the samples were kept in the total electron yield mode under an ultrahigh vacuum at $5 \times 10^{-10}$ mbar. The resolving power of the grating was typically $\mathrm{E} / \triangle \mathrm{E}=1000$, and the photon flux was $1 \times 10^{-10}$ photons per s. Spectra were collected at energies from 386.8 to $440.2 \mathrm{eV}$ in $0.2 \mathrm{eV}$ energy steps.

The sample was initially treated with the $\mathrm{H}_{2}$ gas at $400{ }^{\circ} \mathrm{C}$ for 3 hours, and then was treated with a mixture gas of $\mathrm{N}_{2} / \mathrm{H}_{2}(\mathrm{vol} / \mathrm{vol}=3 / 1)$ at 120,180 and $240{ }^{\circ} \mathrm{C}$ for 1 hour, respectively, after which it was transferred to the analysis chamber for XANES measurement (without being exposed to air). The XANES raw data were normalised by a procedure consisting of several steps. First, the photon energy was calibrated from the 4f spectral peak of a freshly sputtered gold wafer, and then substrate a line to set the pre-edge to be zero. Finally, the spectra were normalised to yield an edgejump to one.

\section{$\mathbf{N}_{2}$ isotope exchanged study}

$\mathrm{N}_{2}$ isotope exchanged study was conducted on a HEL made continuous trickle bed reactor (mode FlowCAT), connected with on-line mass spectroscopy. The $\mathrm{Ru} / \mathrm{TiO}_{2}$ catalyst $(200 \mathrm{mg}$ ) was located in the middle of the tubular reactor with quartz wool plugs on both the sides. The ${ }^{14} \mathrm{~N}_{2}$ and ${ }^{15} \mathrm{~N}_{2}$ gases were passed in downward direction with velocity controlled by mass-flow controllers, with both the ${ }^{14} \mathrm{~N}_{2}$ and ${ }^{15} \mathrm{~N}_{2}$ flow rates of $8 \mathrm{~cm}^{3}(\mathrm{STP})$ minutes ${ }^{-1}$ and atmospheric pressure. The flow rates are respectively calibrated by using a soap film bubble flowmeter. Temperature programming surface reaction was performed from 50 to $400{ }^{\circ} \mathrm{C}$ with ramping rate of $15{ }^{\circ} \mathrm{C} / \mathrm{min}$. The effluent of the gas was passing to a mass spectroscopy (MS) with the stream volume carefully controlled by a needle valve. The MS mode is HPR-20 QIC Benchtop Gas Analysis System. The MS testing mode is Multiple Ion Detection (MID) mode. Mass fragments of $\mathrm{m} / \mathrm{z}=28\left({ }^{14} \mathrm{~N}_{2}\right), 29\left({ }^{14} \mathrm{~N}^{15} \mathrm{~N}\right)$ and $30\left({ }^{15} \mathrm{~N}_{2}\right)$ were monitored.

\section{Theoretical and Computational Details}

DFT parameters. Density functional theory (DFT) was used to perform the energetics and theoretical analyses of the reaction mechanism. To account for the strong on-site Coulomb interaction of localized d-electrons, DFT+U method was used, with an additional Hubbard-like term (U) added to 
the DFT terms. All DFT + U calculations were performed using spin-polarised Kohn-Sham formalism with generalised gradient approximation (GGA) of Perdew-Burke-Ernzerhof (PBE), as implemented in VASP 5.4.4 code $^{39-41}$. From previous works, the value of intra-atomic coulomb term minus exchange term $(\mathrm{U}-\mathrm{J}$ ) was chosen to be $4.0 \mathrm{eV}$ to reproduce the correct strongly correlated systems $^{42,43}$. The valence electronic states of all atoms were expanded in a plane-wave basis set with a cutoff energy of $400 \mathrm{eV}$, and gamma points was used for Brillouin Zone integration. Atomic positions were optimised by conjugate gradient algorithm until the forces were less than $0.03 \mathrm{eV} / \AA$ for all intermediates and transition states. Vibrational analysis was performed to test the imaginary frequency and vibration modes to confirm the CI-NEB results ${ }^{44}$.

Computational models. The anatase $\mathrm{TiO}_{2}(101)$ slab was represented as a $\mathrm{p}(3 \times 4)$ slab with two OTi-O layer and the bottom one is fixed. It has been shown that such large model is enough to accommodate $\mathrm{Ru}_{19}$ cluster and reduce the interactions between neighbouring adsorbed $\mathrm{Ru}$ clusters ${ }^{33}$. $\mathrm{Ru}_{19}$ is the size-matched multilayer $\mathrm{Ru}$ cluster that contains $h c p(0001)$ facet, which would be the most abundant exposed surface for small $\mathrm{Ru}$ nanoparticles and accommodate $\mathrm{N}_{2}$ and $\mathrm{H}_{2}$ simultaneously. And the adsorption energy of $\mathrm{Ru}_{19}$ on $\mathrm{TiO}_{2}(101)$ is as high as $-5.88 \mathrm{eV}$ by following equation, $E_{\text {ads }}=$ $E\left(\mathrm{Ru}_{19} / \mathrm{TiO}_{2}(101)\right)-E\left(\mathrm{TiO}_{2}(101)\right)-E\left(\mathrm{Ru}_{19}\right)$, Indicating $\mathrm{Ru}_{19}$ can be stably anchored. So we choose $\mathrm{Ru}_{19} / \mathrm{TiO}_{2}$ to model the catalytic process. The DIPOL tag was set to 3 to switch on dipole corrections to the total energy along the $\mathrm{z}$-direction. All the supercell slabs were repeated periodically with a $15 \AA$ vacuum layer between the images in the direction of the surface normal.

\section{Reference}

1 Shaver, M. P. \& Fryzuk, M. D. Activation of molecular nitrogen: coordination, cleavage and functionalization of $\mathrm{N}_{2}$ mediated by metal complexes. Adv. Synth. Catal. 345, 1061-1076 (2003).

2 Erisman, J. W., Sutton, M. A., Galloway, J., Klimont, Z. \& Winiwarter, W. How a century of ammonia synthesis changed the world. Nat. Geosci. 1, 636-639 (2008).

3 Hori, M. \& Mori, M. Synthesis of heterocycles utilizing $\mathrm{N}_{2}-\mathrm{TiCI}_{4}-\mathrm{Li}$-TMSCI. J. Org. Chem. 60, 1480-1481 (1995).

4 Vol'pin, M. E., Shur, V. B. \& Berkovich, E. G. Transformations of molecular nitrogen into aromatic amines under the action of titanium compounds. inorg. Chim. Acta 280, 264-274 (1998).

5 Kitano, M. et al. Ammonia synthesis using a stable electride as an electron donor and reversible hydrogen store. Nat. Chem. 4, 934-940 (2012).

6 Aika, K., Hori, H. \& A., O. Activation of nitrogen by alkali metal promoted transition metal 1. ammonia synthesis over ruthenium promoted by alkali metal. J. Catal. 27, 424-431 (1972).

7 H., S. Short history and present trends of Fischer-Tropsch synthesis. Appl. Catal. A 186, 3-12 (1999). 
8 Kunkes, E. L., Simonetti, D. A., West, R. M., Serrano-Ruiz, J. C., Gärtner, C. A., Dumesic, J. A. . Catalytic conversion of biomass to monofunctional hydrocarbons and targeted liquid-fuel classes. Science 322, 417-421 (2008).

9 Mellmer, M. A. et al. Solvent-enabled control of reactivity for liquid-phase reactions of biomass-derived compounds. Nat. Catal. 1, 199-207 (2018).

10 Vispute, T. P., Zhang, H., Sanna, A., Xiao, R. \& Huber, G. W. Renewable chemical commodity feedstocks from integrated catalytic processing of pyrolysis oils. Science 330, 1222-1227 (2010).

11 Xu, C., Arancon, R. A., Labidi, J. \& Luque, R. Lignin depolymerisation strategies: towards valuable chemicals and fuels. Chem. Soc. Rev. 43, 7485-7500 (2014).

12 Li, C., Zhao, X., Wang, A., Huber, G. W. \& Zhang, T. Catalytic transformation of lignin for the production of chemicals and fuels. Chem. Rev. 115, 11559-11624 (2015).

13 Luo, Z., Wang, Y., He, M. \& Zhao, C. Precise oxygen scission of lignin derived aryl ethers to quantitatively produce aromatic hydrocarbons in water. Green Chem. 18, 433-441 (2016).

14 Shao, Y. et al. Selective production of arenes via direct lignin upgrading over a niobiumbased catalyst. Nat. Commun. 8, 16104 (2017).

15 Omotoso, T., Boonyasuwat, S. \& Crossley, S. P. Understanding the role of $\mathrm{TiO}_{2}$ crystal structure on the enhanced activity and stability of $\mathrm{Ru} / \mathrm{TiO}_{2}$ catalysts for the conversion of lignin-derived oxygenates. Green Chem. 16, 645-652 (2014).

16 Liu, G. et al. MoS2 monolayer catalyst doped with isolated Co atoms for the hydrodeoxygenation reaction. Nat. Chem. 9, 810-816 (2017).

17 Huang, Y.-B., Yan, L., Chen, M.-Y., Guo, Q.-X. \& Fu, Y. Selective hydrogenolysis of phenols and phenyl ethers to arenes through direct $\mathrm{C}-\mathrm{O}$ cleavage over ruthenium-tungsten bifunctional catalysts. Green Chem. 17, 3010-3017 (2015).

18 Newman, C. et al. Effects of support identity and metal dispersion in supported ruthenium hydrodeoxygenation catalysts. Appl. Catal. A 477, 64-74 (2014).

19 Cui, X. et al. Highly selective hydrogenation of arenes using nanostructured ruthenium catalysts modified with a carbon-nitrogen matrix. Nat. Commun. 7, 11326 (2016).

20 Li, Z., Assary, R. S., Atesin, A. C., Curtiss, L. A. \& Marks, T. J. Rapid ether and alcohol C-O bond hydrogenolysis catalyzed by tandem high-valent metal triflate + supported Pd catalysts. J. Am. Chem. Soc. 136, 104-107 (2014).

21 Bergem, H., Xu, R., Brown, R. C. \& Huber, G. W. Low temperature aqueous phase hydrogenation of the light oxygenate fraction of bio-oil over supported ruthenium catalysts. Green Chem. 19, 3252-3262 (2017).

22 Omotoso, T. O., Baek, B., Grabow, L. C. \& Crossley, S. P. Experimental and first-principles evidence for interfacial activity of $\mathrm{Ru} / \mathrm{TiO}_{2}$ to toluene. ChemCatChem 9, 2642 - 2651 (2017).

23 Gilkey, M. J., Brady, C., Vlachos, D. G. \& Xu, B. Characterization of Oxidation States in Metal/Metal Oxide Catalysts in Liquid-Phase Hydrodeoxygenation Reactions with a Trickle Bed Reactor. Ind. Eng. Chem. Res. 57, 5591-5598 (2018).

24 Nelson, R. C. et al. Experimental and theoretical insights into the hydrogen-efficient direct hydrodeoxygenation mechanism of phenol over $\mathrm{Ru} / \mathrm{TiO}_{2}$. ACS Catal. 5, 6509-6523 (2015).

Will, C. \& Back, R. A. Stability of Di-imide. Nature 241, 43 (1973). 
26 Foner, S. N. \& Hudson, R. L. Diimide-Identification and Study by Mass Spectrometry. J. Chem. Phys. 28, 719-720 (1958).

27 Kalescky, R., Kraka, E. \& Cremer, D. Identification of the strongest bonds in chemistry. $J$. Phys. Chem. A 117, 8981-8995 (2013).

28 Jime'nez, I., Gago, R. \& Albella, J. M. Spectroscopy of $\pi$ bonding in hard graphitic carbon nitride films: superstructure of basal planes and hardening mechanisms. Phys. Rev. B 62, 4262-4264 (2000).

29 Chen, G. et al. Interfacial electronic effects control the reaction selectivity of platinum catalysts. Nat. Mater. 15, 564-569 (2016).

30 Luksirikul, P., Tedsree, K., Moloney, M. G., Green, M. L. \& Tsang, S. C. Electron promotion by surface functional groups of single wall carbon nanotubes to overlying metal particles in a fuel-cell catalyst. Angew, Chem, Int, Ed, 51, 6998-7001 (2012).

31 Elmasides, C., Kondarides, D. I., Grünert, W. \& Verykios, X. E. XPS and FTIR study of $\mathrm{Ru} / \mathrm{Al}_{2} \mathrm{O}_{3}$ and $\mathrm{Ru} / \mathrm{TiO}_{2}$ catalysts: reduction characteristics and interaction with a methaneoxygen mixture. J. Phys. Chem. B 103, 5227-5239 (1999).

32 Li, H.-J., Yeh, C.-H. \& Ho, J.-J. The catalytic adsorption and dissociation of carbon dioxide on a double icosahedral Ru19 nanocluster - A theoretical study. Chem. Phys. Lett. 585, 149$152(2013)$.

33 Zhang, S.-T. et al. Density functional theory study on the metal-support interaction between $\mathrm{Ru}$ cluster and anatase $\mathrm{TiO}_{2}(101)$ surface. J. Phys. Chem. C 118, 3514-3522 (2014).

34 Honkala, K. et al. Ammonia synthesis from first-principles calculations. Science 307, 555558 (2005).

35 Ma, X. L., Liu, J. C., Xiao, H. \& Li, J. Surface single-cluster catalyst for $\mathrm{N}_{2}$-to- $\mathrm{NH}_{3}$ thermal conversion. J. Am. Chem. Soc. 140, 46-49 (2018).

36 Liu, J. C. et al. Heterogeneous $\mathrm{Fe}_{3}$ single-cluster catalyst for ammonia synthesis via an associative mechanism. Nat. Commun. 9, 1610 (2018).

37 Chang, C.-R., Wang, Y.-G. \& Li, J. Theoretical investigations of the catalytic role of water in propene epoxidation on gold nanoclusters: A hydroperoxyl-mediated pathway. Nano Res. 4, 131-142 (2010).

38 Chang, C.-R., Huang, Z.-Q. \& Li, J. The promotional role of water in heterogeneous catalysis: mechanism insights from computational modeling. WiREs: Comput. Mol. Sci. 6, 679-693 (2016).

39 Kresse, G. \& Joubert, D. From ultrasoft pseudopotentials to the projector augmented-wave method. Phys. Rev. B 59, 1758-1775 (1991).

40 Kresse, G. \& Furthmüller, J. Efficient iterative schemes for ab initio total-energy calculations using a plane-wave basis set. Phys. Rev. B 54, 11169-11186 (1996).

41 Perdew, J. P., Burke, K. \& Ernzerhof, M. Generalized gradient approximation made simple. Phys. Rev. Lett. 77, 3865-3868 (1996).

42 Anisimov, V. I., Aryasetiawan, F. \& Lichtenstein, A. First-principles calculations of the electronic structure and spectra of strongly correlated systems: dynamical mean-field theory. J. Phys. Condens. Matter 9, 7359-7367 (1997). 
43 Tang, Y., Zhao, S., Long, B., Liu, J.-C. \& Li, J. On the nature of support effects of metal dioxides $\mathrm{MO}_{2}(\mathrm{M}=\mathrm{Ti}, \mathrm{Zr}, \mathrm{Hf}, \mathrm{Ce}, \mathrm{Th})$ in single-atom gold catalysts: importance of quantum primogenic effect. J. Phys. Chem. C 120, 17514-17526 (2016).

44 Henkelman, G., Uberuaga, B. P. \& Jónsson, H. A climbing image nudged elastic band method for finding saddle points and minimum energy paths. J. Chem. Phys. 113, 9901-9904 (2000).

\section{Acknowledgements}

H.D. thanks SCG Chemicals Co., Ltd. and SCG Packaging Co., Ltd. (Thailand) for funding. Y.Z. thanks the National Natural Science Foundation of China (21878008), the Fundamental Research Funds for the Central Universities (BUCTRC201807). X.L.M. thanks Beijing Natural Science Foundation (2184105), China Postdoctoral Science Foundation (Nos. 2018T110088, 2017M610863). J.D. acknowledges support from the National Natural Science Foundation of China (Grant No. 11605225) and the Jianlin Xie Foundation of the Institute of High Energy Physics, Chinese Academy of Sciences. J.-C.B. thanks SCG Chemicals Co., Ltd. (Thailand) for funding. We also thank Hefei Light Source and Shanghai Light Source for use of the instruments and Diamond Light Source for access and support in use of the electron Physical Science Imaging Centre (EM16969, 17397) that contributed to the results presented here. J. L thanks National Natural Science Foundation of China (Nos. 21433005, 91645203, and 21590792). The calculations were performed using the supercomputers at Tsinghua National Laboratory for Information Science and Technology. We also thank Prof. Yadong Li for providing characterisation resources and Shufang Ji for performing ICP analysis. We thank Dr. Chunping Chen for performing TPR measurement, Mr. Wei-Che Lin for helping with fixed-bed reactions and Mr. Yusen Yang for assisting FTIR measurements.

\section{Author Contributions}

H.D. conceived the idea, designed and carried out the synthesis, characterisations and catalytic reactions, analysed the data and wrote the manuscript. J.C.L. and X.L.M. performed DFT calculations and wrote the manuscript. Y.Z. carried out catalytic reactions and analysed the data. M.X. and D.M. performed in situ XPS and FTIR measurements and analysed the data. J.D, X.Z. and D.C. performed in-situ XPS measurement and data analysis. J.Z. helped design the experiments and analysed the data. C.A., M.D. and A.K. performed the TEM measurement. Y.-K.P. performed acidity analysis. T.I. conceived the idea and anticipated discussion. J.-C.B. regulated the experiments and anticipated discussion. J.L., S.C.E.T and D.O.H. supervised the project, helped design the experiments, analysed the data and wrote the manuscript. All the authors commented on the manuscript and have given approval to the final version of the manuscript.

\footnotetext{
Additional information

Supplementary Information is available in the online version of the paper. Reprints and permissions information is available online at www.nature.com/reprints. Correspondence should be addressed to D.O.H. or to S.C.E.T. or to J. L.
}

Competing financial interests

The authors declare no competing financial interests. 
